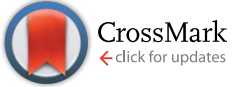

Cite this: Nanoscale, 2014, 6, 11553

Received 22nd June 2014

Accepted 31st July 2014

DOI: $10.1039 / c 4 n r 03482 a$

www.rsc.org/nanoscale

\section{Magnetic nanoparticle-based therapeutic agents for thermo-chemotherapy treatment of cancer}

\begin{abstract}
Aziliz Hervault ${ }^{\mathrm{ab}}$ and Nguyễn Thị Kim Thanh*ab
Magnetic nanoparticles have been widely investigated for their great potential as mediators of heat for localised hyperthermia therapy. Nanocarriers have also attracted increasing attention due to the possibility of delivering drugs at specific locations, therefore limiting systematic effects. The enhancement of the anti-cancer effect of chemotherapy with application of concurrent hyperthermia was noticed more than thirty years ago. However, combining magnetic nanoparticles with molecules of drugs in the same nanoformulation has only recently emerged as a promising tool for the application of hyperthermia with combined chemotherapy in the treatment of cancer. The main feature of this review is to present the recent advances in the development of multifunctional therapeutic nanosystems incorporating both magnetic nanoparticles and drugs, and their superior efficacy in treating cancer compared to either hyperthermia or chemotherapy as standalone therapies. The principle of magnetic fluid hyperthermia is also presented.
\end{abstract}

${ }^{a}$ UCL Healthcare Biomagnetic and Nanomaterials Laboratories, 21 Albermarle Street, London W1S 4BS, UK. E-mail: ntk.thanh@ucl.ac.uk
${ }^{b}$ Department of Physics and Astronomy, University College London, Gower Street, London WC1E 6BT, UK

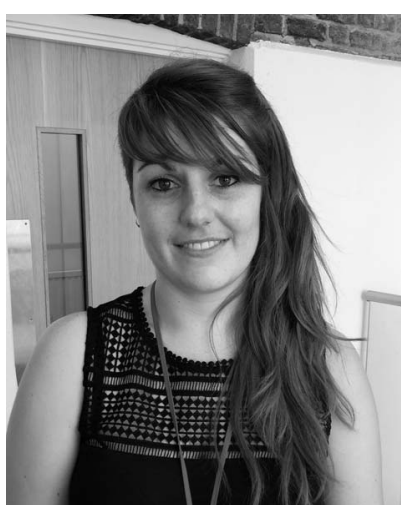

Aziliz Hervault obtained her engineering degree and the equivalent research masters degree in materials science from the "Ecole Européenne de Chimie, Polymères et Matériaux" of Strasbourg and the University of Strasbourg, France in 2013. Currently, she is doing a PhD at University College London under the supervision of Professor Nguyen T. K. Thanh. Her current research projects focus on developing new magnetic nanoparticle-based therapeutic agents for hyperthermia therapy with combined chemotherapy in the treatment of cancer.

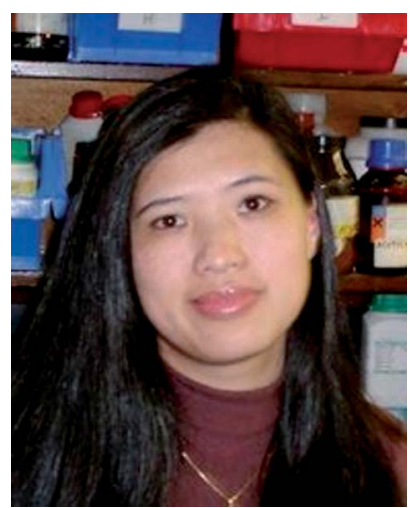

Professor Nguyen T. K. Thanh FRSC MInstP is Professor of Nanomaterials at University College London, U.K. (http:// www.ntkthanh.co.uk). She has over 13 years of research experience in synthesis and biofunctionalisation of inorganic nanoparticles for biomedical applications. She has been an invited speaker at over 100 international conferences and research departments and institutions all over the world. She has served on organisations and scientific committees for many major international conferences on nano-particles research (e.g., Scientific Chair of Faraday Discussion 175: "Physical Chemistry of Functionalised Biomedical Nanoparticle" in 2014 in UK, http://rsc.li/fd175; and organizer of Biohybrid NanoMaterials - Design and Applications Symposium, ICMAT, Singapore, June 2015, http://www.mrs.org.sg/). She was the Guest Editor of a Philosophical Transactions of the Royal Society A themed issue on "Nanoparticles" published in September 2010. Recently she edited a seminal book: "Magnetic nanoparticles: From fabrication to clinical applications" published by CRC Press/Taylor and Francis in 2012, http://www.crcpress.com/ product/isbn/9781439869321. She was also the Guest Editor of Nanoscale themed issue "Functional nanoparticles for biomedical applications" published in 2013. 


\section{Introduction}

Nanoparticles (NPs) are defined as particles that have one or more physical dimensions under $100 \mathrm{~nm}$. Due to their small size, and particularly due to their increasing surface-to-volume ratio, the properties of nano-sized materials will differ from the ones of the bulk material (i.e. optic, catalytic, magnetic and electronic properties). Thanks to their inherent properties, magnetic nanoparticles (MNPs) have been developed as magnetic resonance imaging (MRI) contrast agents, ${ }^{1,2}$ and potential new cancer therapies such as magnetic fluid hyperthermia, ${ }^{3,4}$ and nanovectors for controlled drug delivery. ${ }^{5,6}$ NPs can also be designed to combine several therapeutic functions (hyperthermia and drug delivery), ${ }^{7,8}$ or therapeutic and diagnostic functions (so-called theranostics). ${ }^{\mathbf{9}, 10}$ Scientists have been attempting to understand the structure and property relationship of NPs to harness their properties. ${ }^{11,12}$ Indeed, controlling the composition, size and shape of the NPs via syntheses would allow tailoring and tuning the desired properties. ${ }^{\mathbf{1 3 - 1 6}}$

Because of their numerous advantages, MNPs and especially iron oxide NPs, which have been approved by US Food and Drug Administration, have attracted great interest for their applications in biomedicine. ${ }^{17}$ Indeed, iron oxide NPs are relatively easy to synthesise, biocompatible, non-toxic, chemically rather stable and can be superparamagnetic. The two main forms of iron oxide are $\gamma-\mathrm{Fe}_{2} \mathrm{O}_{3}$ (maghemite) and $\mathrm{Fe}_{3} \mathrm{O}_{4}$ (magnetite). The phenomenon of local or general rise of the body temperature above its normal value is known as hyperthermia. It can be used as a medical treatment, called hyperthermia therapy or thermotherapy, in which body tissues are exposed to slightly higher temperatures in order to damage or kill cancer cells by provoking cell apoptosis, ${ }^{\mathbf{1 8 , 1 9}}$ or to make cancer cells more sensitive to the effects of radiation ${ }^{20}$ and/or certain anti-cancer drugs. ${ }^{20,21}$ Apoptosis, also called programmed cell death, is a distinct mode of cell death, whereby the cells in normal tissues triggered their self-destruction in response to a signal. ${ }^{19}$ Contrary to the necrosis, there is no associated inflammation. Apoptosis also occurs spontaneously in cancer cells, thereby retarding the growth of the tumour, and can be increased when subjected to heat, irradiation or anti-cancer drugs.

The concept of hyperthermia was already in practice many centuries ago by Greeks, Egyptians and Romans. ${ }^{22,23}$ In 3000 BC, Indian medical practitioners used local and whole body hyperthermia. During the $19^{\text {th }}$ century, it was observed that fever can cause tumour regression, ${ }^{23}$ and scientific study was performed on hyperthermia to treat cervical cancer. ${ }^{22}$ The use of hyperthermia as a treatment for cancer was taken more seriously in the 1970s, and controlled clinical trials on induced hyperthermia began to be conducted. It was then discovered that cancer cells have greater sensitivity to hyperthermia as compared to normal cells. Indeed, healthy tissues are able to withstand temperatures of $42-45{ }^{\circ} \mathrm{C}$, in contrast to cancer cells which undergo apoptosis at those temperatures. ${ }^{24,25}$ Treatment at temperatures above $46{ }^{\circ} \mathrm{C}$ is called thermo-ablation. It leads to the necrosis of cancer cells, but may also affect healthy cells. In contrast to apoptosis that is a natural process, necrosis is a form of cellular damage that results in the premature death of cells in body tissues and initiates an inflammatory response in the surrounding environment. ${ }^{26,27}$ It is almost always harmful and can even be deadly (i.e. can lead to septicaemia or gangrene). Thus, thermoablation in this temperature range is not desirable due to the potentially important side effects on healthy tissues, and hyperthermia induced apoptosis is therefore preferable.

While the specific mechanism of cell killing by hyperthermia is still unknown, the thermal energy needed for induction of cell death has been found to be close to the energy needed for protein denaturation, leading to the conclusion that the main cytotoxic effect of hyperthermia is based on the denaturation of membrane and cytoplasmic proteins. ${ }^{28,29}$ Membrane alteration and cytoskeletal damage such as cell rounding and blebbing (which is a typical feature of apoptosis) are some of the most apparent manifestations of thermal damage at the cellular level. Another important consequence of protein denaturation is the alteration of DNA synthesis and repair. Higher sensitivity to heat has been observed for cells in the mitosis phase (with damage to the mitotic apparatus), ${ }^{28,29}$ which makes cancer cells more susceptible to heat than normal cells as they undergo faster cell division. The tumour selective effect of hyperthermia is also due to the physiological differences between normal and tumour tissues. Indeed, the architecture of the vasculature in tumour is disorganised and abnormal compared to normal tissue (one of the principal features being the lower vessel density). In many cases, tumour blood flow remains greater than in the surrounding healthy tissues, especially in small tumours (tumour blood flow generally decreases with increasing tumour size). ${ }^{30}$ However, when hyperthermia is applied at temperatures over $42{ }^{\circ} \mathrm{C}$, tumour blood flow tends to decrease while in normal tissue it significantly increases. This decreased blood flow results in a lower heat dissipation rate, and hence the temperature in a tumour will rise faster than in normal tissue..$^{30,31}$ This difficulty in dissipating heat may cause cancer cells to undergo apoptosis, while physiological temperatures are more easily maintained in normal tissues. ${ }^{32}$ The disorganised structure of tumour vasculature also leads to oxygen and nutrient deprivation. ${ }^{33}$ Moreover, regions of hypoxia, energy deprivation and acidosis are even more favoured with the reduction of the blood flow caused by heat exposure. ${ }^{28,34}$ These tumour micro-environmental factors also make cancer cells more sensitive to hyperthermia, ${ }^{35}$ in addition to its direct cytotoxicity.

In fact, hyperthermia may increase or decrease the tumour oxygenation depending on the temperature and the exposure time. ${ }^{36}$ Hyperthermia applied at temperatures lower than $42{ }^{\circ} \mathrm{C}$ is more likely to provoke an increase in the tumour blood flow, thereby improving the oxygen supply. This phenomenon can be exploited to make cells more sensitive to radiotherapy (radiosensitivity is favoured by good tissue oxygenation) or chemotherapy (drug delivery is increased by higher perfusion). ${ }^{\mathbf{2 8 , 3 7}}$ The synergistic effect of hyperthermia with radiotherapy has been demonstrated in various clinical trials, ${ }^{38,39}$ and shows better efficacy than either hyperthermia ${ }^{40}$ or radiotherapy alone. ${ }^{41}$ This synergism induces an increase in cell death even at 
temperatures lower than temperatures normally applied in hyperthermia therapy. This thermal radiosensitisation is explained by the increasing blood flow, and by the fact that $\mathrm{S}$ phase cells (cells undergoing DNA replication) and hypoxic cells (cells that survive the hypoxia and acidic environment of tumour), normally resistant to radiation, are highly sensitive to heat destruction. ${ }^{\mathbf{2 0 , 2 8 , 4 2}}$ The synergistic effect of hyperthermia with chemotherapy has also been demonstrated in clinical trials. ${ }^{43-45}$ The increase in blood flow provoked by hyperthermic treatment results in an increase in drug concentration in the tumour area, an increase in intracellular drug uptake and enhanced DNA damage. ${ }^{20}$ Moreover, heat has been found to enhance the cytotoxic effect of many anti-neoplastic drugs. ${ }^{21}$ Consequently, hyperthermia is often used as an adjuvant therapy with radio- and/or chemotherapy. ${ }^{37}$

A wide range of heat sources and treatments for hyperthermia are being developed for clinical applications. There are three main types of hyperthermia: local hyperthermia, regional hyperthermia and whole-body hyperthermia. The hyperthermia technique is chosen depending on the location, the depth and the stage of malignancy. In whole-body hyperthermia, the entire body is heated up. This method is often chosen in the case of deep-seated and propagated metastases. The heating can be achieved through hot water baths, thermal chambers or infrared radiators. ${ }^{\mathbf{4 6}}$ However, as may be expected, this treatment may lead to major side effects given the fact that heat is not selective. Therefore, careful control of the skin temperatures is needed. Even though temperatures of $41.8-42{ }^{\circ} \mathrm{C}$ can be achieved, and the method is clinically realisable, the medical care needed to ensure a safe procedure in the case of whole-body hyperthermia is much greater than in local or regional therapy. ${ }^{37}$ This has resulted in its limited use as a standalone procedure. Regional hyperthermia is used to deliver heat to advanced stage tumours. Thermal perfusion, external applicators or arrays of multiple applicators (microwave antennas) are example of devices used in regional hyperthermia. ${ }^{\mathbf{4 6 7}}$ Local hyperthermia is often used to treat localised tumours either superficially or in accessible body cavities. It is the less invasive technique. Local hyperthermia systems are based on applicators or antennas emitting mostly microwaves, ultrasounds or radio waves. ${ }^{46,48}$ Recently, a new technology has been developed for local hyperthermia using MNPs as mediators of heat. This technology is called Magnetic Fluid Hyperthermia (MFH).

MFH consists of a colloidal suspension of MNPs which is injected into the tumour where the MNPs will be internalised by the cancer cells. ${ }^{49}$ Applying an external alternative magnetic field (AMF) will cause the NPs to heat and kill the cancer cells. The first clinical trial was conducted in 2003 on 14 patients suffering from glioblastoma multiform..$^{50}$ The promising results led to a phase II study involving 66 patients with glioblastoma multiforme. Results showed that hyperthermia therapy using MNPs can be applied safely and is effective for the treatment of cancer, but also that the overall survival following diagnosis of first tumour recurrence is longer compared to conventional therapies. ${ }^{38} \mathrm{MFH}$ possesses numerous advantages over traditional techniques. First of all, the injection of MNPs is less invasive and can be potentially injected and concentrated anywhere in the body, allowing the treatment of all kinds of tumours with limited side effects. Moreover, once the MNPs have been internalised into the cancer cells, they are able to remain inside the cells even after creation of daughter cells. In fact, $50 \%$ of the amount of MNPs present in parent cells end up in the daughter cells, ${ }^{51}$ meaning that a subsequent hyperthermic treatment can be applied without large reinjection of MNPs. Magnetic targeting can be used to drive the MNPs toward the targeted cancer regions. The MNPs can also be functionalised with a recognition moiety (i.e. antibodies, proteins) in order to increase the selectivity to malignant cells, therefore increasing the internalisation of the MNPs in the cancer cells. ${ }^{52}$ The potential of MFH as a treatment for cancer is clear, but can even be improved by designing MNPs with multiple therapeutic functions, i.e. hyperthermia and drug delivery. Indeed, drug delivery by means of NPs also has numerous advantages over traditional chemotherapy. The major drawback of chemotherapy being the non-specificity of the drugs, healthy organs and cells may also be strongly damaged during the therapy. With NPs, the possibility of targeting specific locations in the body allows the reduction of the chemotherapeutic dose to reach the concentrations needed in the tumour for an effective therapy. In addition, the concentration of drugs at non-targeted sites is reduced therefore minimizing undesirable side effects. ${ }^{53}$ Taking advantage of the synergistic effect of the combined thermo-chemotherapy, MNP-based therapeutic agents for hyperthermia and controlled drug delivery are really promising candidates in the treatment of cancer.

This review aims to demonstrate the great potential of magnetic nanosystems for the combination of hyperthermia and chemotherapy, by reporting and discussing promising examples of the literature. The principle of $\mathrm{MFH}$ as well as recent studies on MNPs for hyperthermia applications is presented as a basis for understanding the mechanism of magnetic nanoparticle-mediated hyperthermia therapy.

\section{Magnetic nanoparticles for hyperthermia therapy}

\subsection{Mechanism of heat}

The conversion from magnetic energy to thermal energy in MNPs subjected to an AC magnetic field can be due to several mechanisms.

In multi-domain NPs (ferri- or ferromagnetic material), the production of heat is due to hysteresis losses, which can be seen as the amount of energy dissipated during a magnetisation cycle. ${ }^{52,54}$ A ferromagnet is formed by magnetic domains (Weiss domains) in which the moments of atoms are all parallel to each other to maintain a lower energy state, while a ferrimagnet is formed by magnetic domains with opposing magnetic moments of different amplitudes. When an external magnetic field is applied, the magnetic domains tend to align themselves in the same direction as the applied field. The saturation magnetisation is reached as soon as each moment of each domain is aligned toward this direction. When the applied field is removed, the magnetisation does not revert back to zero, and 
this is the remanent magnetisation. In order to reduce the magnetisation to zero again, a magnetic field with a precise intensity needs to be applied, and it is called coercivity (or coercive field). The magnetisation curve of a ferromagnet is represented by a hysteresis loop (Fig. 1) and the hysteresis losses can be measured by integrating the area of the hysteresis loop.

Superparamagnetism is a form of magnetism that occurs in ferromagnetic or ferrimagnetic materials, when they are in the form of sufficiently small NPs. Indeed, bulk materials basically contain multiple magnetic domains due to their large size. However, small enough NPs are single-domain particles, which can be regarded as one giant magnetic moment composed of all magnetic moments of the atoms forming the NPs. Superparamagnetic NPs are preferred over ferri- and ferromagnetic NPs for biomedical applications, because they do not retain any magnetisation once the magnetic field is removed (Fig. 2). Single-domain NPs dissipate heat through relaxation losses which fall in two modes: Néel relaxation and Brownian relaxation. The mechanism of relaxation depends on the size of the NPs but also on the magnetic material (due to its anisotropy constant). ${ }^{55}$ Néel relaxation comes from the reorientation of the magnetic moment in the same direction as the applied magnetic field with each field oscillation. ${ }^{56,57}$ The Néel relaxation time $\tau_{\mathrm{N}}$ is given by the following equation:

$$
\tau_{\mathrm{N}}=\tau_{0} \exp \left(\frac{K V}{k_{\mathrm{B}} T}\right)
$$

where $\tau_{0}=10^{-9} \mathrm{~s}, K$ is the anisotropy constant, $V$ is the volume of the magnetic particle, $k_{\mathrm{B}}$ is the Boltzmann constant and $T$ is the temperature. Néel relaxation is strongly size-dependent. A smaller particle requires less energy for the rotation of its magnetic moment, consequently the Néel relaxation mechanism will be very important.

Brownian relaxation is caused by the friction arising from the rotation of the particle itself in the carrier liquid. ${ }^{\mathbf{5 6 , 5 7}}$ The

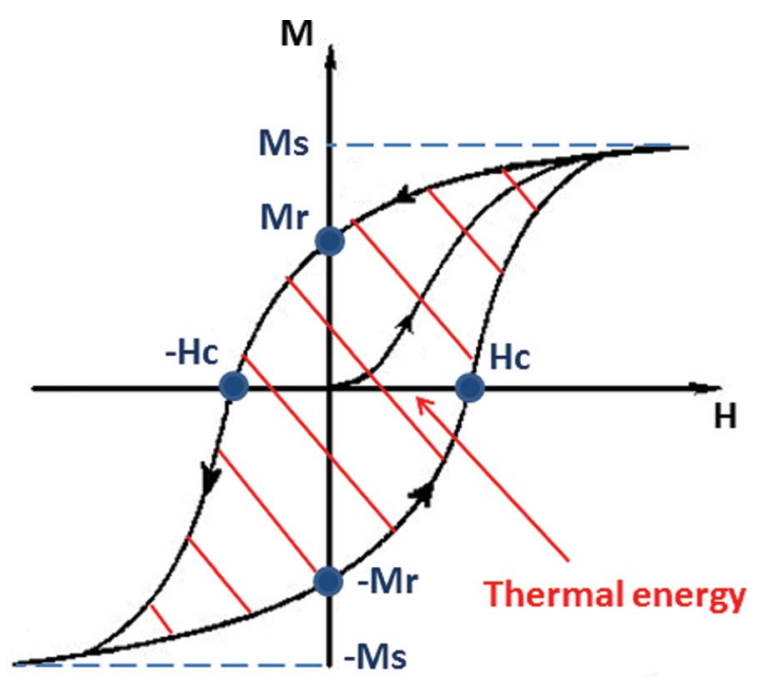

Fig. 1 Hysteresis loop of a ferromagnet. The area of the hysteresis loop represents the energy dissipated during a magnetisation cycle.

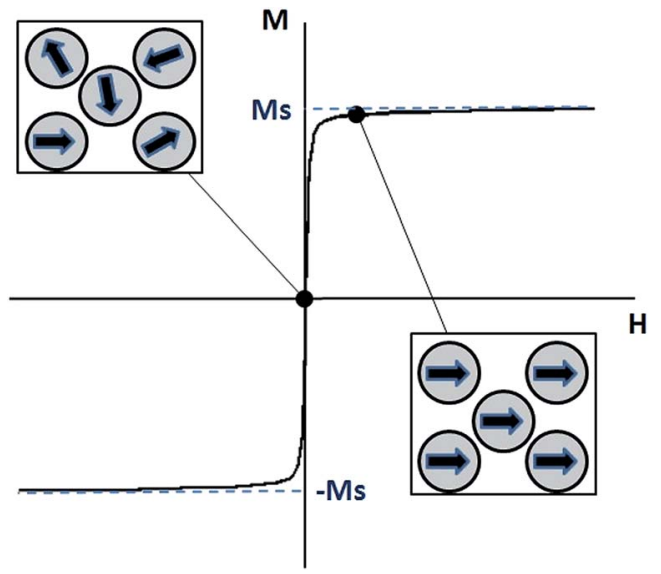

Fig. 2 Typical curve for a superparamagnetic material (squares show the orientation of the moment of single-domain nanoparticles with increasing field strength).

Brownian relaxation time $\tau_{\mathrm{B}}$ is expressed by the following equation:

$$
\tau_{\mathrm{B}}=\frac{3 \eta V_{\mathrm{H}}}{k_{\mathrm{B}} T}
$$

where $\eta$ is the viscosity of the liquid carrier, $V_{\mathbf{H}}$ is the hydrodynamic volume of the particle, $k_{\mathrm{B}}$ is the Boltzmann constant and $T$ is the temperature. The Brownian relaxation mechanism is size-dependent too and also strongly viscosity-dependent. ${ }^{58} \mathrm{~A}$ higher viscosity of the liquid medium will slow down the rotation of the particles. Generally, losses by Néel relaxation prevail in small NPs while the Brownian regime dominates in larger NPs. ${ }^{56,59}$ In fact, the Brownian losses are not exclusively found in superparamagnetic NPs. ${ }^{54}$ For hyperthermia applications, it is better to have NPs relaxing essentially through the Néel mechanism, because when internalised in the cells, a change in the viscosity medium can happen and/or free rotation of the particles can be prevented.

A combination of the two magnetic relaxation times gives the overall effective relaxation time $\tau$ of the particles: ${ }^{56}$

$$
\tau=\frac{\tau_{\mathrm{B}} \tau_{\mathrm{N}}}{\tau_{\mathrm{B}}+\tau_{\mathrm{N}}}
$$

Application of an AMF oscillating faster than the relaxation time of the MNPs induces the release of heat from the MNPs caused by the delay in the relaxation of the magnetic moment. ${ }^{56}$ The heat dissipation $(P)$ is given by the following equation: ${ }^{60}$

$$
P=\mu_{0} \chi^{\prime \prime} f H^{2}
$$

where $P$ is the heat dissipation value, $\mu_{0}$ is the permeability of free space, $\chi^{\prime \prime}$ is the AC magnetic susceptibility (imaginary part), $f$ is the frequency of the applied AC magnetic field, and $H$ is the strength of the applied AC magnetic field.

Quantification of the power dissipation of magnetic nanoparticles in an AMF is usually done by measuring the specific absorption rate (SAR) expressed in $\mathrm{W} \mathrm{g}^{-1}$ (also referred to as specific loss power): ${ }^{56}$ 


$$
\mathrm{SAR}=C \frac{\Delta T}{\Delta t}
$$

where $C$ is the specific heat capacity of the sample and $\Delta T / \Delta t$ is the initial slope of the time-dependent heating curve. SAR highly depends on various parameters such as the size, size distribution, shape, chemical composition and surface modification, saturation magnetisation of the particles; and frequency and amplitude of the applied magnetic field. A high heating potential is crucial for the clinical use of $\mathrm{MFH}$, because it would require a smaller amount of NPs to be injected into the patient. Therefore, engineering MNPs (control their physical and chemical properties using synthesis) to obtain an exceptional SAR value is highly desirable. ${ }^{61-64}$ For example, most ferri- and ferromagnetic materials require application of a high magnetic field to use a full loop area, which is not realisable clinically due to physiological and technical restrictions. Therefore, the use of multi-domain NPs results in low SAR values. On the other hand, superparamagnetic NPs which produce heat via Néel and Brownian relaxation mechanisms are able to generate a much larger quantity of heat and thus a higher SAR at lower field amplitudes. Hergt et al. suggested that the optimum size to get particles with a high SAR value is near the transition from superparamagnetic to ferromagnetic behaviour. ${ }^{65}$ Considering the equation of the heat dissipation value, it is clear that SAR values increase with the frequency $f$ and the field amplitude $H$ of the applied field. However, in order to apply hyperthermia safely to patients and avoid any detrimental effect on healthy tissues due to electromagnetic radiation exposure, the $\mathrm{Hf}$ factor should not exceed a threshold which was experimentally estimated to equal $5 \times 10^{9} \mathrm{~A} \mathrm{~m}^{-1} \mathrm{~s}^{-1}$. ${ }^{66}$

The comparison between SAR values obtained by different research groups can be challenging. Indeed, there is a lack of standardised protocol to measure the heating ability of the MNPs. The ideal device for accurate measurement of the SAR would be an adiabatic setup, but because it is expensive and time-consuming, most of the research groups use non-adiabatic and often home-made setups which results in more sources of inaccuracies and increased variability of the SAR values. ${ }^{67-69}$ Also, each research group measures the nanoparticles' heating capabilities under different field conditions. Indeed, there are no standards for the frequency and field amplitude of the applied field used during the measurement which makes the SAR values difficult to compare with each other. Pankhurst et al. introduced a new parameter able to allow a more direct comparison of the heating efficiency of superparamagnetic nanoparticles, the intrinsic loss power (ILP). ${ }^{4}$ The ILP is obtained by normalizing the SAR by the frequency and field amplitude, and is therefore independent of the magnetic field parameters.

\subsection{Nanoparticle delivery to the tumour site}

MNPs must be delivered in a secure pathway specifically to the cancer site and should be retained in the tumour in order to reach a sufficient concentration for effective hyperthermia therapy (as well as for drug delivery). Three main approaches for the delivery of NPs can be distinguished: direct injection, systematic passive and active delivery.

The direct injection method consists of injecting directly the magnetic fluid into the tumour. The intratumoural injection is the simplest way to administer the NPs, and is therefore the most used in in vivo studies ${ }^{70,71}$ and has even already been used in clinical trials of $\mathrm{MFH}^{39,72}$ The main advantage of this technique is the ease of achieving a high and localised concentration of MNPs in the tumour. However, the intratumoural injection of MNPs is only possible in localised and superficial or easily accessible tumour, thus this approach is limited in the investigation of many cancers, and particularly advanced stage cancers. Moreover, direct injection results in a non-homogeneous MNP distribution in the tumour, which makes the complete regression of the tumour difficult. ${ }^{73}$

Systematic delivery is achieved by injecting MNPs intravenously that will accumulate preferentially in tumour tissue due to the enhanced permeability and retention (EPR) effect. ${ }^{74,75}$ The EPR effect was first reported by Matsumura and Maeda in $1986,{ }^{76}$ and was further investigated and described to a greater extent by Maeda et al. ${ }^{77-82}$ The EPR effect rests on the facts that solid tumours exhibit a defective vascular architecture and that lymphatic clearance from the interstitium of tumour tissue is impaired. The former results in an enhanced vascular permeability which facilitates nutrient and oxygen supply to satisfy the demand of growing tumours, while the latter results in the retention of macromolecules in the tumour. Therefore, solid tumours possess a leaky vasculature compared to normal tissues, which facilitates the extravasation of NPs. Consequently, when NPs are injected intravenously, they can leak out the blood vessel to deposit in the tumour, and are retained here for a long time due to impaired lymphatic drainage. MNPs can also be injected into the artery supplying the blood stream to the targeted organ in order to improve the deposition of MNPs in the tumour. To take advantage of the EPR effect, the MNPs should be able to circulate long enough in the blood stream. For this purpose, NPs should have a hydrodynamic diameter smaller than $200 \mathrm{~nm}$ to avoid liver clearance and bigger than 50 $\mathrm{nm}$ to avoid renal clearance. ${ }^{83}$ The coating of the NPs can also play an important role in the permeability and retention of the NPs in cancer cells, as well as in the blood retention time of the NPs. In a recent study, superparamagnetic iron oxide NPs were coated with two different polymers for MRI applications: alkalitreated dextran (ATD) and carboxymethyl dextran (CMD) ${ }^{84} \mathrm{~A}$ much more efficient labeling of macrophages was obtained with the ADT-coated NPs. After $4 \mathrm{~h}$, ADT-coated NPs exhibited a labeling efficiency superior to $95 \%$ against only $20-30 \%$ for the CMD-coated NPs. Protein adsorption onto the surface of NPs may accelerate the clearance by the reticulo-endothelial system $^{53}$ and affect the bio-reactivity of the NPs. ${ }^{85}$ An effective coating can prevent or at least minimize protein attachment onto the surface of NPs. Finally, NPs have to be stable in the biological medium to avoid aggregation and conserve the hydrodynamic size which ensures them a long blood circulation time. The systematic delivery of NPs via the EPR effect results in a more global distribution of the MNPs in the tumour compared to an intratumoural injection, and also permits treating of most 
of the types of cancers. However, the principal disadvantage of this method is the difficulty to reach a concentration of NPs sufficient enough for effective treatment, yet the amount of NPs injected cannot be further increased, in order to avoid nonnegligible MNP toxicity. In order to achieve higher deposition and improve tumour uptake of the NPs, they can be driven magnetically inside the body via an external magnetic field and/ or can be functionalised with a targeting ligand for active delivery.

Active delivery consists of improving the specificity of the NPs by functionalising their surface with a targeting moiety that binds to cell receptors. It usually results in a higher NP accumulation and cellular uptake in the targeted cancer cells. Among the most commonly used targeting agents, we can find antibodies, ${ }^{\mathbf{8 6 , 8 7}}$ antibody fragments, ${ }^{\mathbf{8 8 , 8 9}}$ receptor ligands, ${ }^{\mathbf{9 0 , 9 1}}$ peptides ${ }^{\mathbf{9 2 , 9 3}}$ and aptamers. ${ }^{\mathbf{9 4 , 9 5}}$ The superiority of targeted MNPs in cancer treatments has already been proven many times. For example, in a recent study, ${ }^{96}$ iron oxide NPs were coated with dextran and functionalised with an anti-human epidermal growth factor receptor (HER2) aptamer for targeted hyperthermia. The results showed that a 90 -fold lower dose of the aptamer-functionalised NPs was necessary to produce a $60 \%$ decrease in the HER2-overexpressing cell viability compared to the non-tagged NPs. Such an effect was not observed in the control cell line.

Another targeting system which can be used to improve the accumulation of MNPs into the tumour site is magnetic targeting, also called magnetophoresis. This technique uses an external magnetic field placed near the tumour to magnetically attract the NPs toward this area. Magnetic targeting has already shown efficiency in in vivo studies. ${ }^{97,98}$

\subsection{Magnetic nanomaterials for hyperthermia therapy}

Numerous materials have been investigated for their potential use in magnetic hyperthermia, such as Fe, Co, and Ni metallic NPs and their oxide. Pure metals have the highest saturation magnetisation, but have limited use in biomedical applications due to their inherent toxicity and poor chemical stability (quick oxidation process). Research into metal ferrites has shown good chemical stability, SAR values and magnetic properties, making a new class of potential candidates for magnetic hyperthermia. ${ }^{61}$ The effects of Co or Zn dopant on metal ferrite NPs have also been investigated, showing improved SAR. For example, $15 \mathrm{~nm}\left(\mathrm{Zn}_{0.4} \mathrm{Mn}_{0.6}\right) \mathrm{Fe}_{2} \mathrm{O}_{4}$ NPs synthesised by thermal decomposition exhibit an increased anisotropy and a saturation magnetisation of $175 \mathrm{emu}^{-1}$ resulting in a SAR value almost four times higher than that of Feridex NPs. ${ }^{99}$ Despite the superior magnetic properties of metallic NPs, iron oxide NPs are still the most studied magnetic material for hyperthermia applications, due to their low toxicity, good biocompatibility, ease of synthesis and surface functionalisation. The most used synthetic routes to make iron oxide NPs are the thermal decomposition of organometallic iron precursors and the coprecipitation of $\mathrm{Fe}^{2+}$ and $\mathrm{Fe}^{3+}$ aqueous salt in the presence of a base. The different synthetic methods of MNPs for biomedical applications, including the main parameters (such as the precursor, time and temperature of the reaction, solvent, ligand, etc.) influencing the MNP properties, and NP functionalisation have already been reviewed many times. ${ }^{17,100-103}$

A number of MNP properties may influence their hyperthermia potential such as the composition, shape, coating, magnetic properties, size and size distribution. Some recent studies have been carried out to investigate the influence of these properties on the resulted hyperthermia treatment effectiveness, and Kolhatkar et al. recently reviewed parameters that can be varied to tune the magnetic properties of NPs. ${ }^{\mathbf{1 0 4}}$

Carrey et al. recently published a method to identify suitable or unsuitable materials for hyperthermia. ${ }^{\mathbf{1 0 5}}$ A new approach for the exact calculation of the hysteresis loop is presented and models for the calculation of the optimum parameters of MNPs for magnetic hyperthermia, such as the optimum anisotropy, are provided.

Sedlacik et al. synthesised magnetite NPs by a microwave irradiation-assisted solvothermal method, using different nucleating agents (ammonium acetate, ammonium carbonate and aqueous ammonia). ${ }^{\mathbf{1 0 6}}$ The highest saturation magnetisation was obtained for magnetite NPs nucleated with aqueous ammonia due to a pure cubic $\mathrm{Fe}_{3} \mathrm{O}_{4}$ spinel phase and the absence of non-magnetic impurities. The lower saturation magnetisation obtained for the two other NPs was attributed to the presence of coexisting phases with different magnetic properties, such as goethite. Again, the highest SAR value was recorded for the NPs nucleated with aqueous ammonia, most likely caused by their higher saturation magnetisation, their smaller size and narrow size distribution compared to the particles obtained with the other nucleating agents. GonzalesWeimuller et al. studied the influence of the size (ranging from 5 to $14 \mathrm{~nm}$ ) and polydispersity on the SAR of iron oxide NPs subjected to an AMF (frequency $=400 \mathrm{kHz}$; amplitude $\left.=24.5 \mathrm{kA} \mathrm{m}^{-1}\right){ }^{14}$ The highest SAR value of $447 \mathrm{~W} \mathrm{~g}^{-1}$ $\left(\mathrm{ILP}=1.86 \mathrm{nHm}^{2} \mathrm{~kg}^{-1}\right)$ was obtained for the $14 \mathrm{~nm}$ NPs. Moreover, the lower the polydispersity, the higher the SAR value will be, no matter the NP size. For larger NPs where hysteresis losses are the main mechanism of heat, the SAR value increases as the NP size decreases. ${ }^{107}$ The heating power in $\mathrm{MgFe}_{2} \mathrm{O}_{4}$ NPS was found to be strongly size-dependent, with a SAR maximum value when the particle size was $10 \mathrm{~nm} \cdot{ }^{108}$ De la Presa et al. synthesised maghemite NPs of $8 \mathrm{~nm}, 11 \mathrm{~nm}, 13 \mathrm{~nm}$ and $14 \mathrm{~nm}$ by a co-precipitation method, and studied the influence of NP concentration, size, coating, liquid carrier, field amplitude and frequency on the SAR value. ${ }^{109}$ For each NP size, the concentration of NPs dispersed in water does not seem to influence the SAR in the studied iron concentration range ( 6 to $300 \mathrm{mg} \mathrm{mL}^{-1}$ ) with a field amplitude of $7.5 \mathrm{kA} \mathrm{m}^{-1}$ and a frequency of $522.7 \mathrm{kHz}$. Increasing the size of the NPs resulted in an increased SAR value: for $8 \mathrm{~nm}$ to $11 \mathrm{~nm}$ NPs, the SAR is increased four times, from $10 \mathrm{~W} \mathrm{~g}^{-1}$ to $40 \mathrm{~W} \mathrm{~g}^{-1}$. For $11 \mathrm{~nm}$ to $13 \mathrm{~nm}$ NPs, the SAR is only increased from $40 \mathrm{~W} \mathrm{~g}^{-1}$ to $55 \mathrm{~W} \mathrm{~g}^{-1}$. Finally, in order to investigate the influence of the medium viscosity, the NPs were dispersed in two different media, water and agar. For the smaller NPs, the viscosity has negligible influence on SAR values, but for the bigger NPs, the SAR values drop when they are in the most viscous medium (agar). This is 
due to the fact that Neel relaxation is mainly responsible for the production of heat in small NPs, and is not influenced by the carrier viscosity. In the bigger NPs, both Néel and Brownian relaxation take part in the heating process. A viscous medium will slow down the particle rotation, therefore limiting the heat production mechanism by Brownian relaxation. However, tissues in the human body can have different viscosities. Thus, it is important to choose NPs with a maximal heating efficiency independent of the media viscosity, meaning that the NPs' mechanism of heat should be principally by Néel relaxation losses. They concluded that the optimum size for a maximized viscosity-independent SAR value is around $12 \mathrm{~nm}$ for maghemite NPs.

The influence of the shape on the MNP heating properties has been less extensively studied than the influence of the size. Song et al. synthesised magnetite NPs by thermal decomposition in octadecene in the presence of oleic acid, and varied the amount of surfactant and refluxing time to get highly monodisperse spherical (9.5 nm) and quasi-cubical (9.6 nm) MNPs. ${ }^{110}$ The results showed that the quasi cubical MNPs have a higher SAR value compared to the spherical NPs with an equivalent size and prepared under the same conditions. This phenomenon most likely comes from a bigger magnetic core volume of the quasi cubical MNPs, and higher crystallinity. A huge enhancement of heating performances is observed for multi-core flower- shaped maghemite NPs of $24 \mathrm{~nm}$ (constituted of smaller grains of $11 \mathrm{~nm}$ ), with a SAR of $1992 \mathrm{~W} \mathrm{~g}^{-1} \cdot{ }^{111}$

MNPs are usually coated with a ligand to improve their biocompatibility and their colloidal stability, because NP aggregation would modify the NP properties (and therefore their heating properties), and once injected into the body, it would probably result in the clearance of the MNPs by the reticulo-endothelial system before they could reach the desired location. The choice of the ligand is important because it can modify the magnetic properties of the NPs. For example, Larumbe et al. showed that silica coating on magnetite NPs resulted in a decrease of the magnetic properties and the SAR value, due to an enhancement of the spin disorder surface effects caused by the silica coating. ${ }^{112}$ Thus, the surface coating needs to be optimised to get the best hyperthermic agents. In a recent study, magnetite NPs with controlled particle size ( $9 \mathrm{~nm}, 19 \mathrm{~nm}$ and $31 \mathrm{~nm}$ ) and mPEG surface coating thickness (by varying the molecular weight: $2000 \mathrm{Da}, 5000 \mathrm{Da}$, and $20000 \mathrm{Da}$ ) were synthesised by thermal decomposition. ${ }^{64}$ The heating efficiency was observed to decrease with increasing polymer chain length, except for the biggest NPs. Indeed, the $31 \mathrm{~nm}$ NPs coated with $2000 \mathrm{Da}$ mPEG agglomerates, which means that the polymer has too short chains to provide good colloidal stability due to a strong magnetic dipole-dipole interaction. Similar behaviour is observed for the measured SAR values. The highest

Table 1 Summary of the properties of the magnetic materials described in Section 2.3 with their corresponding SAR, ILP values and AMF parameters

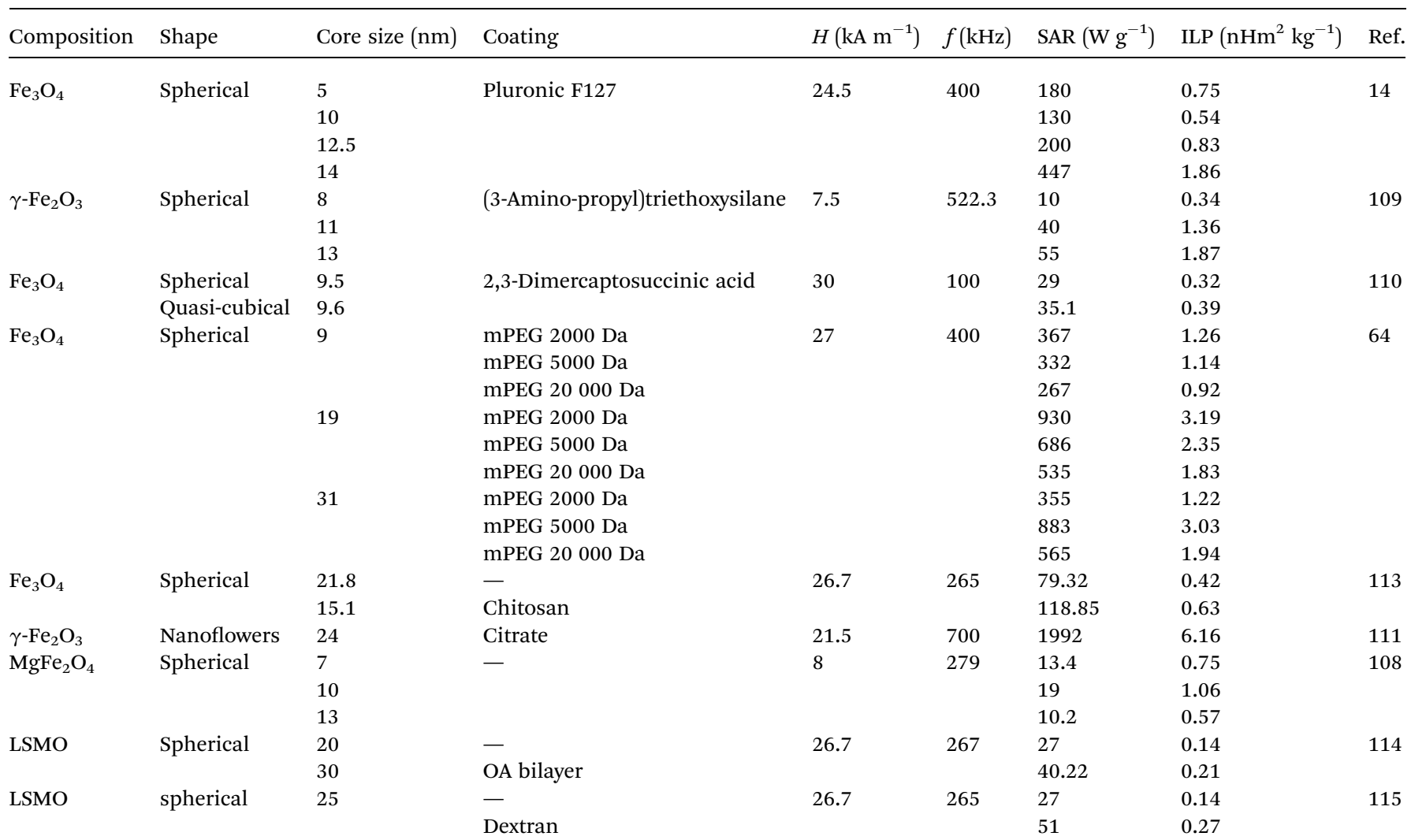


SAR value achieved was $930 \mathrm{~W} \mathrm{~g}^{-1}$ for the $19 \mathrm{~nm}$ NPs coated with 2000 Da mPEG and the lowest was $267 \mathrm{~W} \mathrm{~g}^{-1}$ for the 9 $\mathrm{nm}$ NPs coated with 20000 Da mPEG. Therefore, these results show that the SAR can be significantly improved by optimizing the surface coating and the magnetic core size. The effect of chitosan coating on magnetite NPs has also been studied recently, showing an improved SAR compared to bare magnetite NPs. ${ }^{113}$ A bilayer of oleic acid has been shown to improve the hyperthermia properties of $\mathrm{La}_{0.7} \mathrm{Sr}_{0.3} \mathrm{MnO}_{3}$ (LSMO) NPs, ${ }^{114}$ arising from an improved colloidal stability of the NP suspension at physiological pH. This study also shows the effect of ionic strength on the heating efficiency of the NPs. A drop of the SAR is observed due to decreasing colloidal stability when $\mathrm{NaCl}$ is added to the NP suspension (the higher the $\mathrm{NaCl}$ concentration, the lower the SAR). A dextran coating also enhances the hyperthermia potential of LSMO NPs. ${ }^{115}$ It is believed to be due to the ability of the dextran coating to retain the superparamagnetic fraction of the LSMO NPs and the improved colloidal stability of the coated NPs.

A summary of the main parameters, including SAR and ILP values of the magnetic materials described in the Section 2.3, is given in Table 1 . Heating efficiencies of commercially available ferrofluids have been studied and tabulated elsewhere. ${ }^{4}$

It is important to control the temperature during magnetic hyperthermia treatment, in order to avoid overheating of the surrounding healthy tissues. However, precise control of the temperature can be difficult to achieve, and therefore, magnetic materials with a maximum self-heating temperature are very attractive for hyperthermia applications. The Curie temperature $\left(T_{\mathrm{c}}\right)$ is an intrinsic property of magnetic materials. Above this temperature, the magnetic system becomes paramagnetic (Fig. 3) and therefore heating stops.

By choosing a material with a $T_{\mathrm{c}}$ close to the hyperthermia temperature range and adjusting it to the desired therapeutic temperature (the $T_{\mathrm{c}}$ of a magnetic system can be modified to a certain extent with the chemical composition), the heating of the tumour can be controlled and the temperature can be maintained at a constant desired value for self-controlled hyperthermia treatment. For example, the $T_{\mathrm{c}}$ of $\mathrm{Mn}$-ferrites can be decreased by replacing magnetic ions with non magnetic $\mathrm{Ti}^{4+}$ ions $\left(\mathrm{Mn}_{1+x} \mathrm{Ti}_{x} \mathrm{Fe}_{2} \mathrm{O}_{4}\right)$, from $300{ }^{\circ} \mathrm{C}$ at $x=0$ to about $35{ }^{\circ} \mathrm{C}$ at $x=0.6 .{ }^{116} \mathrm{~A} T_{\mathrm{c}}$ of $46{ }^{\circ} \mathrm{C}$ was obtained at $x=0.55$. Among the magnetic materials with a tunable $T_{\mathrm{c}}$ in the therapeutic temperature range, we can find:

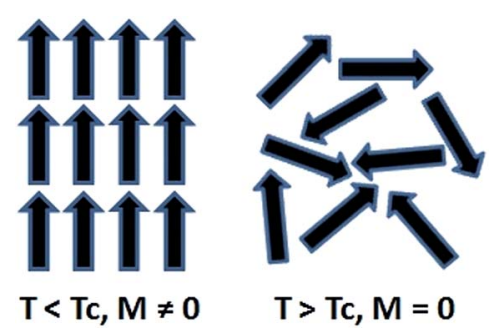

Fig. 3 Schematic representation of the moments of atoms of a ferromagnet below and above its Curie temperature in the absence of an applied magnetic field.
$\mathrm{La}_{1-x} \mathrm{Sr}_{x} \mathrm{MnO}_{3}$ whose $T_{\mathrm{c}}$ increases with an increasing $\mathrm{Sr}$ content, ${ }^{117}$ Gd-substituted $\mathrm{Zn}$-ferrite $\left(\mathrm{ZnGd}_{x} \mathrm{Fe}_{2-x} \mathrm{O}_{4}\right)$ whose $T_{\mathrm{c}}$ increases with an increasing Gd content and was found around $45{ }^{\circ} \mathrm{C}$ at $x=0.02,{ }^{118} \mathrm{Ni}_{1-x} \mathrm{Cr}_{x}$ whose $T_{\mathrm{c}}$ increases with a decreasing $\mathrm{Cr}$ content and was found equal to $44{ }^{\circ} \mathrm{C}$ at $x=5.63,{ }^{119}$ and $\mathrm{Mg}_{1+x} \mathrm{Fe}_{2-2 x} \mathrm{Ti}_{x} \mathrm{O}_{4}$ whose $T_{\mathrm{c}}$ decreases with a decreasing Fe content and was found around $46{ }^{\circ} \mathrm{C}$ for $x=0.37 .^{120}$

\subsection{Examples of in vivo application hyperthermia therapy}

Monocyte/macrophage-like cells (Mo/Ma) are tumourhoming cells. They are known to infiltrate tumour sites and have been shown to specifically accumulate in pancreatic tumours when injected intraperitoneally. Basel et al. used Mo/Ma cells to carry core/shell iron/iron oxide NPs directly into the tumour of $\mathrm{C} 57 \mathrm{BL} / 6$ mice injected with Pan02 cells to generate a murine model of disseminated pancreatic cancer. ${ }^{121}$ The Mo/Ma cells loaded with MNPs were therefore injected intraperitoneally, and three days after the injection, the mice were subjected to 20 min of AMF exposure. The mice subjected to the hyperthermia treatment survived significantly longer than the other mice in AMF, Mo/Ma cells or MNPs control groups, with a $31 \%$ increase in lifespan.

Lin et al. used $\mathrm{Mn}-\mathrm{Zn}$ ferrite NPs coated with polyethyleneimine to evaluate the anti-cancer effects of the magnetic fluid with and without combined radiotherapy in vitro and in vivo. ${ }^{122}$ They chose a magnetic fluid with a NP concentration of $10 \mathrm{~g} \mathrm{~L}^{-1}$ because it stabilised around $43{ }^{\circ} \mathrm{C}$ under application of an AMF of frequency $=230 \mathrm{kHz}$ and amplitude $=1 \mathrm{kA} \mathrm{m}^{-1}$. Tumours were grown into the right posterior limb rump of nude mice by injecting exponentially growing HepG 2 cells. The magnetic fluid was injected intratumourally following a multipoint injection strategy, and the hyperthermic treatment was applied for $1 \mathrm{~h}$. The volume inhibition rate and mass inhibition rate of the combined group were $87.62 \%$ and $88.62 \%$, respectively, against $41.04 \%$ and $34.20 \%$ for the radiation-alone group and $79.87 \%$ and $77.92 \%$ for the hyperthermia-alone group. The in vivo experiments revealed good inhibition of the tumour growth, for both hyperthermia alone and the combined treatment.

Ferucarbotran (also called Resovist) consists of clinically approved superparamagnetic iron oxide nanoparticles (SPIONs) coated with carboxydextran developed for contrast-enhanced MRI of the liver. Those NPs can also be used for hyperthermia therapy as they are able to generate heat when subjected to an AMF. Araya et al. injected A549 cells (non small cell lung cancer cell line) in BALB/c nu/nu athymic female nude mice and studied the anti-cancer effects of ferucarbotran-mediated hyperthermia. ${ }^{123}$ Ferucarbotran NPs were injected intratumourally and the temperature was maintained at $43-45{ }^{\circ} \mathrm{C}$ for 20 min by application of an AMF. Even when complete tumour suppression was not fully achieved, the tumour volume was significantly suppressed.

Some clinical trials have been performed on MNPs for hyperthermia therapy and have been summarized by Thiesen \& Jordan in $2008^{50}$ and by Zhao et al. in 2013. ${ }^{\mathbf{1 2 4}}$ 


\section{Magnetic nanosystems for thermo- chemotherapy}

\subsection{Enhancement effect of the combined therapy}

The enhancement of chemotherapy effects with application of concurrent hyperthermia is called thermo-chemosensitisation. Several mechanisms are involved in this thermal enhancement, such as increased antineoplastic drug accumulation in tumours and enhanced drug cytotoxicity (improved intracellular uptake of drugs and increased sensitivity of cells to drugs). ${ }^{\mathbf{1 2 5 , 1 2 6}}$ The first one is due to the physiological effect of mild hyperthermia on tumour vasculature, including an increased blood flow, perfusion, and blood vessel pore size of the already leaky tumour vasculature. All these factors facilitate drug extravasation in tumour tissues. The mechanisms responsible for the enhanced drug cytotoxicity are not yet fully understood, but generally involve improved intracellular uptake of drugs due to increased cell membrane permeability, inhibition of DNArepair of the chemically induced lethal or sublethal damage, and acceleration of the cytotoxic chemical reaction in the case of alkylating or platinum-based antineoplastic agents at elevated temperatures. ${ }^{21}$ Fig. 4 summarizes the mechanisms behind the synergistic effect of hyperthermia and chemotherapy.

Several studies have demonstrated that the thermal enhancement of the cytotoxic activity of many anti-cancer agents is maximized at mild hyperthermia temperatures (40.5$\left.43{ }^{\circ} \mathrm{C}\right) .{ }^{127}$ Chemotherapeutic drugs can be classified into four different categories depending on the way heat affects their cytotoxicity: ${ }^{128}$

- Agents exhibiting a linear increase in cytotoxicity with increasing temperature: alkylating antineoplastic drugs (nitrogen mustards, nitrosoureas and thiothepa), platinumbased chemotherapeutic drugs (i.e. cisplatin), mitorantrone and mitomycin $\mathrm{C}$ are part of this category.

- Agents showing a threshold temperature effect: they do not undergo a linear increase but only a little change in cytotoxicity with increasing temperatures until a threshold of $42-43{ }^{\circ} \mathrm{C}$. Above this threshold, a synergetic effect is observed. This is the case of adriamycin, bleomycin and actinomycin $\mathrm{D}$.

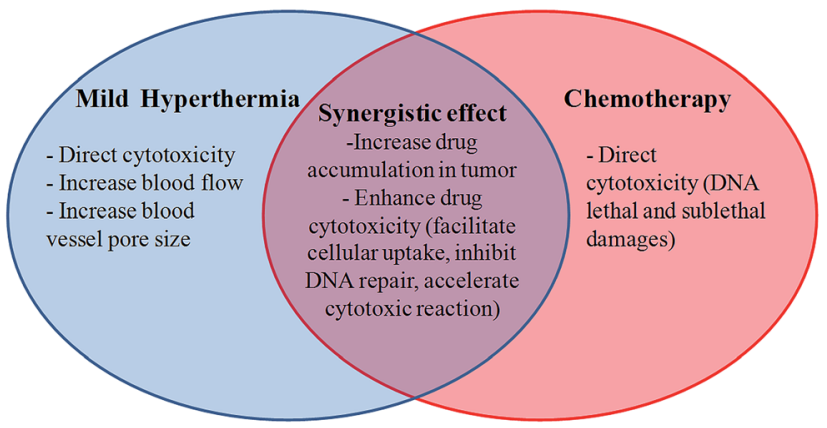

Fig. 4 Mechanisms responsible for the synergistic effect of the combined therapy.
- Agents not presenting any change in cytotoxicity with higher temperatures: antimetabolites, methoterate, 5-fluorouracil, amsacrine, and vinca alkaloids (vincristine and vinblastine) show temperature-independent action.

- Agents that are not cytotoxic at $37^{\circ} \mathrm{C}$, but become cytotoxic with increasing temperatures. This type of cytotoxicity is characteristic of cysteamine, amphotericin B and lidocaine.

Different studies have aimed at evaluating the thermal enhancement of the cytotoxic activity of some chemotherapeutic drugs as well as the mechanisms behind. The thermal enhancement of cisplatin and adriamycin cytotoxicity was evaluated in vitro using a human bladder cancer cell line. ${ }^{\mathbf{1 2 9}}$ Mild hyperthermia alone $\left(41^{\circ} \mathrm{C}\right)$ and low drug concentration (20 $\mu \mathrm{g} \mathrm{mL}{ }^{-1}$ of cisplatin or $4 \mu \mathrm{g} \mathrm{mL}^{-1}$ of adriamycin) did not have any cell killing effect. However, the anti-tumour effect of the combined therapy was significantly higher than either hyperthermia or drug alone, using the same drug concentrations and hyperthermia temperature. Indeed, the survival rate in the case of the combined treatment was the same as that of a 10-fold higher concentration of cisplatin or adriamycin administered alone. These results indicate that the quantity of drugs used in chemotherapy for the treatment of cancer can be effectively reduced by combination with mild hyperthermia, thereby limiting the side effects of the treatment. The mechanisms of action of the two drugs are the following: cisplatin interacts with DNA to form DNA intrastrand crosslink adducts (DNA platination). ${ }^{\mathbf{1 3 0}}$ Crosslinks cause DNA replication arrest and apoptotic cell death if they are not repaired. Cisplatin therefore inhibits DNA synthesis and cell division. Adriamycin intercalates into DNA and inhibits the enzyme topoisomerase II resulting in DNA damage and cell death. Adriamycin can also generate free radicals (reactive oxygen species) which damage the cellular membrane, DNA, and proteins and lead to apoptotic cell death. ${ }^{\mathbf{1 3 1}}$ Mechanisms responsible for the thermal cytotoxicity enhancement of both drugs are most likely due to an increase of cellular uptake, therefore DNA damage and possibly inhibition of DNA repair.

Onconase is a cytotoxic ribonuclease which binds to cell surface receptors, degrades ribosomal RNA once internalised to the cell and inhibits protein synthesis causing apoptotic cell death. ${ }^{\mathbf{1 3 2 , 1 3 3}}$ Onconase also suppresses proliferation, is cytotoxic to several tumour cell lines and is synergistic with many anticancer agents. The thermal enhancement of the onconase cytotoxic effect by mild hyperthermia was evaluated in vitro on human lymphoblastoid TK6 cells. The percentage of apoptotic cells was measured after treatment with onconase alone (2 or 5 $\left.\mu \mathrm{g} \mathrm{mL}{ }^{-1}\right)$, hyperthermia alone $\left(40{ }^{\circ} \mathrm{C}\right.$ or $\left.41^{\circ} \mathrm{C}\right)$, for a treatment duration of $24 \mathrm{~h}$ or $48 \mathrm{~h}$, and for the combined treatment. The results are presented in Table 2 .

The increased therapeutic effect of mild hyperthermia with onconase was observed at $41{ }^{\circ} \mathrm{C}$ and even at $40{ }^{\circ} \mathrm{C}$, the temperatures at which the cells were not affected at all. The thermal enhancement mechanism of onconase cytotoxic activity is not known with certainty. However, it is believed that an increase in intracellular uptake of the drug and accelerated kinetics of ribosomal RNA degradation is responsible for the synergistic effect of the therapy. 
Table 2 Percentage of apoptotic cells after $24 \mathrm{~h}$ and $48 \mathrm{~h}$ of treatment

\begin{tabular}{lllrr}
\hline & & \multicolumn{2}{l}{ Temperature } \\
\cline { 3 - 5 } $\begin{array}{l}\text { Treatment } \\
\text { duration }\end{array}$ & $\begin{array}{l}\text { Onconase } \\
\text { concentration }\end{array}$ & $37.5{ }^{\circ} \mathrm{C}$ & $40{ }^{\circ} \mathrm{C}$ & $41{ }^{\circ} \mathrm{C}$ \\
\hline \multirow{2}{*}{$24 \mathrm{~h}$} & $0 \mu \mathrm{g} \mathrm{mL}{ }^{-1}$ & $6 \%$ & $6 \%$ & $25 \%$ \\
& $2 \mu \mathrm{g} \mathrm{mL}^{-1}$ & $13 \%$ & $39 \%$ & $>50 \%$ \\
$48 \mathrm{~h}$ & $5 \mu \mathrm{g} \mathrm{mL}^{-1}$ & $15 \%$ & $49 \%$ & $>55 \%$ \\
& $0 \mu \mathrm{g} \mathrm{mL}^{-1}$ & - & $7 \%$ & $45 \%$ \\
& $2 \mu \mathrm{g} \mathrm{mL}^{-1}$ & $33 \%$ & $54 \%$ & $74 \%$ \\
& $5 \mu \mathrm{g} \mathrm{mL}^{-1}$ & $42 \%$ & $77 \%$ & $85 \%$ \\
\hline
\end{tabular}

The thermal enhancement of melphalan (alkylating agent) and oxaliplatin (platinum-based agent) cytotoxicity was studied in vitro using spontaneous fibrosarcoma FSa-II tumour cells, as a function of treatment time at temperatures between 37 and $44.5{ }^{\circ} \mathrm{C}$ with a constant concentration of melphalan $(0.25 \mu \mathrm{g}$ $\left.\mathrm{mL}^{-1}\right)$ or oxaliplatin $\left(7.5 \mu \mathrm{g} \mathrm{mL}{ }^{-1}\right) \cdot{ }^{134}$ For both drugs, a thermal enhancement was observed (more pronounced in the case of melphalan) which became greater with increasing temperatures or increasing treatment time. The mechanism of the effect of oxaliplatin has been found to be the same as that of cisplatin (formation of DNA intrastrand crosslink adducts which inhibits DNA replication and leads to cell death). Melphalan interacts with DNA to form interstrand crosslink adducts, also causing apoptotic cell death. At physiological temperatures, they observed a constant cell killing effect indicating that cytotoxic reactions occurred at a constant rate. With increasing temperatures, the reaction rate became faster. Thus, at mild hyperthermia temperatures (below $42{ }^{\circ} \mathrm{C}$ ), the mechanisms responsible for the thermal enhancement of the drug cytotoxic activity seem to be mostly an increased rate of chemical reactions leading to cell death, the inhibition of DNA repair of druginduced DNA damage and an enhanced intracellular uptake of drugs. Above $42{ }^{\circ} \mathrm{C}$, hyperthermia has a direct killing effect on cells due to the denaturation of proteins induced by heat. This study also highlights the importance of the thermal dose: the heating temperature and the time of exposure greatly influence the interaction between heat and drug.

Other numerous studies showed a thermal enhancement of drug cytotoxicity. For example, the combined treatment of hyperthermia at $43{ }^{\circ} \mathrm{C}$ for $45 \mathrm{~min}$ and cisplatin or etoposide resulted in more apoptotic cells than hyperthermia or drug alone with a lower concentration of the drug. ${ }^{135}$ Again with cisplatin, the combined treatment was 1.7 times more effective than hyperthermia alone $\left(43{ }^{\circ} \mathrm{C}, 60 \mathrm{~min}\right)$ and 1.4 times more effective than cisplatin alone. ${ }^{136}$ Hyperthermia was in this case applied by means of iron oxide NPs. BCNU (1,3-bis(2-chloroethyl)-1-nitrosourea), an alkylating agent, causes DNA interstrand crosslinks which lead to cell death. The alkylation reaction rate is accelerated by hyperthermia which results in an increased cell death. ${ }^{137} \mathrm{~A}$ comparative study of some of the clinically employed platinum-based anticancer agents (cisplatin, carboplatin and oxaliplatin) demonstrates a cytotoxic thermal enhancement for all of them. ${ }^{138}$ However, a true synergistic effect was observed in the case of cisplatin, while only an additive effect was reported for carboplatin and oxaliplatin. All these studies reveal that the most effective treatment is achieved when hyperthermia and the drug are administered simultaneously, but some exceptions exist. Thus, drug pharmacokinetics has to be investigated to be able to benefit as much as possible from the improved anti-cancer effect of the treatment using a minimum amount of drugs thereby minimizing the toxicity. For instance, gemcitabine needs a time interval of $24 \mathrm{~h}$ between drug administration and application of hyperthermia to obtain a synergistic effect. ${ }^{21}$

There is a concern about the oncogenic potential of many anti-cancer drugs. Hyperthermia combined with chemotherapy has the potential to reduce the risk of treatment-induced secondary cancer because hyperthermia seems to lower oncogenic transformations. Indeed, hyperthermia converts sublethal damage induced by the drug to lethal damage and/or inhibits DNA repair, therefore reducing the expression of transformation. Moreover, cells in S-phase are particularly sensitive to heat, and transformation mainly occurred when cells are in S-phase. Thus, hyperthermia could reduce the frequency of transformation induced by chemotherapy. A study dedicated to the oncogenic potential of hyperthermia combined with either actinomycin D, mitomycin C or carmustine showed a reduction of the drug-induced transformation for a given level of cell killing compared to the administration of the drug alone. ${ }^{139} \mathrm{~A}$ reduction of oncogenic transformations was also reported in the case of melphalan ${ }^{140}$ and cis-platinum. ${ }^{140,141}$

\subsection{Nanosystems for simultaneous hyperthermia and drug release}

Anti-cancer agents are highly cytotoxic for both cancer and healthy tissues. The controlled release of drugs in a localised, targeted area is an important stake in chemotherapy, as it would allow the reduction of systematic exposure therefore minimizing the side effects, and also the reduction of the amount of drug used during the therapy. This becomes possible using nanosystems as a vehicle for drug delivery., ${ }^{9142-146}$ The chemotherapeutic drug is stored and protected in the nanocarrier until it reaches the cancer site, where it is released. The drug is thus harmless to healthy tissues during its circulation in the body, and provided in high concentrations at the desired location.

Different nanoformulations incorporating both MNPs and drugs have been created for the purpose of thermo-chemotherapy. A growing area in drug and gene delivery is the use of stimuli-responsive compounds, and especially thermo-sensitive polymers, to trigger the release of drugs. ${ }^{147}$ The use of MNPs for local hyperthermia is therefore particularly relevant to this purpose. Indeed, the heat produced by the MNPs under application of an AMF will trigger the fast release of the drug, and increase the effectiveness of the treatment due to the synergistic effect of the simultaneous application of hyperthermia and chemotherapy. The incorporation of MNPs also offers the possibility of guiding the magnetic nanosystems in the body to target the tumour by the application of a static external magnetic field. 
Stimuli-responsive polymers, also called smart polymers, have the ability to change properties in response to a change in their environment such as the temperature, $\mathrm{pH}$, light, magnetic field, etc. ${ }^{148}$ Thermo-responsive polymers respond to temperature: they undergo a conformational change at a specific temperature, called the lower critical solution temperature (LCST). Below the LCST, the polymer is in a swollen hydrophilic state and transform to a shrunken hydrophobic state above the LCST by expelling the aqueous content. The most studied polymer for thermo-responsive drug delivery systems is poly $(\mathrm{N}$ isopropylacrylamide) (PNIPAAm) which has a LCST of $32{ }^{\circ} \mathrm{C}$ in water. By varying the ratio of the hydrophilic/hydrophobic comonomer, the LCST of a given polymer can be tuned. ${ }^{\mathbf{1 4 9}}$ This behaviour is therefore used to remotely trigger the release of the drug: by tuning the LCST to be in the hyperthermia temperature range, the drug will be retained at physiological temperature, and release as a consequence of hyperthermia. pH-responsive polymers are also often exploited for drug delivery applications because of the $\mathrm{pH}$ changes found in the human body. The $\mathrm{pH}$ in the tumour environment is often more acidic than the $\mathrm{pH}$ in the blood or healthy tissue. pH-sensitive drug delivery systems can target the tumour site and release their payload due to the $\mathrm{pH}$ difference.

The approach of simultaneous thermo-chemotherapy using magnetic nanosystems is relatively new. Kumar and Mohammad recently reviewed and proposed extending the meaning of the term hyperthermia to cover both hyperthermia therapy and magnetically modulated controlled drug delivery through heating. ${ }^{150}$ In this case, heat is only used as a trigger for drug release. In our context, hyperthermia and chemotherapy therapeutic functions are combined in the same nanosystem taking advantage of the great potential of $\mathrm{MFH}$ and controlled drug delivery in the treatment of cancer, and also benefiting from the synergetic effect of the combined therapy. The most relevant organic/inorganic designs developed so far will be presented, focusing on the most encouraging results of $\mathrm{pH}$ - and/or thermosensitive systems for the triggerable delivery of drugs under application of an external AMF. Among them, we can find core/ shell NPs, liposomes, micelles, and polymeric carriers such as hydrogels or polymeric NPs. Figure 5 displays the most important biologically useful nanosystems for simultaneous thermochemotherapy, which are usually administered intratumourally or intravenously.

\subsection{Different nanosystem designs}

3.3.1 Liposomes. Liposomes are spherical vesicles composed of an aqueous core surrounded by a lipid bilayer. Liposomes are one class of the most attractive and studied systems for drug delivery. Hydrophilic chemotherapeutic drugs can be entrapped in the aqueous compartment, while hydrophobic drugs can be encapsulated in the lipid membrane. Liposomes change the pharmacokinetics of the drug and lower its systematic delivery and toxicity. With the major advancement of long circulation liposomes (by incorporating PEGchains in the lipid bilayer), ${ }^{151}$ liposomal formulation is now able to increase the circulation time of the drug in the body (avoiding clearance by the reticuloendothelial system and renal filtration), and enhance the drug deposition in the tumour via the EPR effect.

Magnetoliposomes are formed by incorporating magnetic nanoparticles into the liposome with the molecules of the drug, either in the core for NPs stable in aqueous solution ${ }^{\mathbf{1 5 2}}$ or in the lipid membrane for NPs in a hydrophobic state. ${ }^{\mathbf{1 5 3}}$ Temperaturesensitive liposomes use specific lipid and polymers to achieve

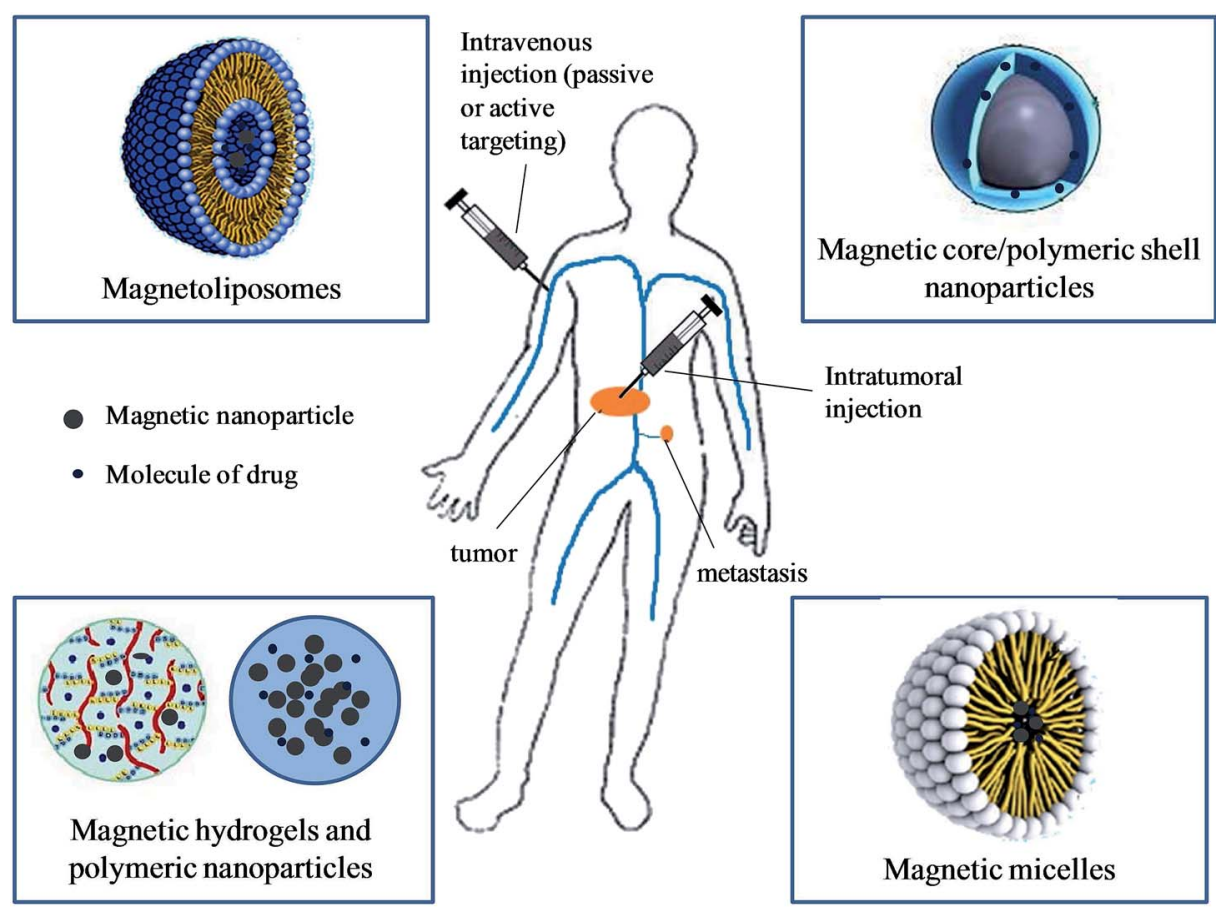

Fig. 5 Important nanosystems for application in thermo-chemotherapy. 
temperature-sensitive release of drugs. Under the phase transition temperature of the bilayer, drugs are retained inside the liposome, until they are released in tumour tissue or vasculature as a consequence of heat causing bilayer disruption. As thermo-sensitive liposomes have been widely investigated for drug delivery, we refer the reader to several well-documented reviews on the subject. ${ }^{\mathbf{1 5 4 - 1 5 6}}$ Thermo-sensitive magnetoliposomes have shown potential efficacy for the combined treatment of cancer. For example, liposomes with MNPs encapsulated in the lipid bilayer and calcein (as a model of hydrophilic drug) loaded into the aqueous compartment have shown interesting "on-demand" release properties. ${ }^{157}$ The release can be triggered repetitively, by switching ON and OFF the AMF, with almost inexistent cargo release when the AMF is turned OFF. This property is due to the reversible permeability change of the lipid bilayer rather than the destruction of the liposome, and is really interesting to control dose, location and time of drug release, with simultaneous magnetic nanoparticles' hyperthermia.

Kulshrestha et al. developed paclitaxel loaded magnetoliposomes and achieved a better cell killing efficacy than magnetoliposomes or paclitaxel loaded liposomes alone. ${ }^{158}$ The liposome lipid bilayer was formed from 1,2-dipalmitoyl-snglycero-3-phosphocholine (DPPC) and 1-palmitoyl-2-oleoyl-snglycero-3-phospho-rac-glycerol (PG) $(9: 1, \mathrm{w} / \mathrm{w})$. The transition temperature of DPPC is $41{ }^{\circ} \mathrm{C}$, while the one of PG is $1{ }^{\circ} \mathrm{C}$. However, adding a small amount of PG proteins to the DPPC lipid bilayer has shown to increase the stability of the bilayer, without lowering too much the transition temperature and thereby minimizing the release of the drug at temperatures lower than the transition temperature. Magnetite NPs coated with citric acid and paclitaxel were successfully encapsulated (83 $\pm 3 \%$ and $74.6 \pm 5 \%$, respectively) into the liposome aqueous compartment. The drug release behaviour was studied under an AC magnetic field at $37{ }^{\circ} \mathrm{C}$ and $43{ }^{\circ} \mathrm{C}$. At $37{ }^{\circ} \mathrm{C}$, only $1.2 \%$ of paclitaxel were released compared to $55.6 \%$ at $43{ }^{\circ} \mathrm{C}$. The in vitro experiments were performed on HeLa cells, and hyperthermia was applied at $42.5 \pm 1{ }^{\circ} \mathrm{C}$ for a duration of 30 min with magnetoliposomes containing $6 \mathrm{mg} \mathrm{mL}^{-1}$ of MNPs only or in combination with $100 \mathrm{nM}$ paclitaxel. The cell viability was decreased by $37 \%$ after the heat treatment alone and by about $50 \%$ for paclitaxel loaded magnetoliposomes without application of an AMF, while the combined treatment resulted in $89 \%$ cell killing. Thus, this liposomal formulation shows promising potential for cancer thermo-chemotherapy, because of its good biocompatibility, the slow drug release at $37^{\circ} \mathrm{C}$, the magnetic nanoparticles' hyperthermia-triggered burst drug release and the synergistic effect of the combined treatment.

3.3.2 Micelles. Surfactants are composed of a hydrophilic head group and a hydrophobic tail. When in aqueous solution, they spontaneously assemble into an aggregate with the polar heads facing the surrounding water and a hydrophobic, waterexcluding core. Hydrophobic drugs can therefore be encapsulated into the micelle core. Drug molecules can even be directly conjugated to the polymer structure via a cleavable link. ${ }^{159}$ As liposomes, micelles extend the circulation time of the drugs in the body, enhance their accumulation via the EPR effect in the tumour and protect them against renal and reticuloendothelial clearance. Micelles can be engineered to be thermo-responsive via incorporation of a thermally sensitive polymer either in the head polar group or the non-polar tail. Micelles have been widely used as drug delivery systems, and several recent good reviews can be found on the subject of polymeric micelles. ${ }^{159-161}$

Micelles with a thermo-sensitive corona are usually used for drug delivery applications. The thermo-sensitive polymer undergoes a conformational change from hydrophilic state to hydrophobic state when it reaches its LCST, therefore destabilizing the micelle structure and allowing the release of the drug. The collapse hydrophobic corona may interact with the cellular membrane resulting in enhanced intracellular uptake. ${ }^{\mathbf{1 6 2}}$ The micelles can be loaded with MNPs and drug at the same time to form magnetic micelles that can be used for hyperthermia with combined chemotherapy.

Kim et al. investigated the potential of thermo-sensitive magnetic micelles for concurrent hyperthermia and drug release: $\quad \operatorname{poly}(\mathrm{N}$-isopropylacrylamide-co-acrylamide)-block-pol$\mathrm{y}(\varepsilon$-caprolactone) (P(NIPAAm-co-AAm)- $b$-PCL) random block copolymer micelles (70 nm) were loaded with magnetite SPIONs (11 nm). ${ }^{163} \mathrm{P}$ (NIPAAm-co-AAm)- $b$-PCL is amphiphilic and PCL forms the hydrophobic tail and will therefore comprise the core of the micelle. The LCST of the micelles was estimated to be $43{ }^{\circ} \mathrm{C}$, but the PCL softening starts at $40{ }^{\circ} \mathrm{C}$. The magnetic micelles were prepared with different weight ratios $(1: 0,1: 0.2$, $1: 0.5,1: 1,1: 2,1: 3,1: 4$, and $1: 5)$ of P(NIPAAm-co-AAm)- $b$ PCL and SPIONs and loaded with doxorubicin (DOX) with a $66 \%$ drug-loading efficiency. It appears that only the weight ratios from $1: 1$ to $1: 3$ gives stable micelle structures. The drug release abilities by heating the micelles (with a $1: 1$ weight ratio of polymer to SPION) via a water bath or magnetic heating were compared. At physiological temperature, the release of DOX was not significant. The amount of DOX released at $43{ }^{\circ} \mathrm{C}$ is at least three times higher when the micelles were subjected to an AMF than heated with a water bath which is due to the direct thermal energy transfer from the SPIONs to the lipid layer. The trigger drug release at $43{ }^{\circ} \mathrm{C}$ (LCST) is due to the dehydration of the polymer outer shell and the relaxation of the PCL core resulting in the shrinkage of the micelle and the expulsion of the drug molecules. This micelle formulation could therefore be employed for the combination of thermo-chemotherapy.

3.3.3 Polymeric nanoformulations. In this section, magnetic NPs encapsulated in either polymeric NPs or hydrogels will be detailed.

Polymeric nanoparticles are of great interest for biomedical applications due to the possibility of controlling and tuning their compositions, structures and properties (i.e. shape, size, surface charge, functionalisation) due to a controlled reaction of polymerisation. ${ }^{\mathbf{1 6 4}}$ Several MNPs and drug molecules can be encapsulated in the same polymeric NP, to be used as agents for thermo-chemotherapy. From the choice of the polymers comprising the NPs as well as the different polymer ratios, new or improved properties can arise, such as thermo-sensitivity, biocompatibility, etc.

An interesting study developed a $\mathrm{pH}$ - and temperaturesensitive nanosystem composed of $10 \mathrm{~nm}$ SPIONs and two anti- 
cancer drugs encapsulated in a poly(D,L-lactic-co-glycolic acid) (PLGA) shell for the combined therapy. ${ }^{\mathbf{1 6 5}}$ The anti-cancer agents, curcumin and 5-fluorouracil (5FU), were loaded with a $71 \%$ and $63 \%$ efficiency, respectively. Curcumin causes a decrease in the mitochondrial membrane potential while 5FU inhibits the synthesis of DNA and RNA. Finally, the NPs were functionalised with folate (its receptors are highly displayed in several carcinomas) and transferrin (transferrin receptors are highly overexpressed in cancer cells) to obtain dual targeted, dual drug loaded MNP-encapsulated PLGA nanovectors (150 $\mathrm{nm})$. The drug release percentage was found higher for both drugs under acidic $\mathrm{pH}$, and reached more than $70 \%$ in the case of curcumin and $80 \%$ in the case of $5 \mathrm{FU}$ after about $80 \mathrm{~h}$. Three different cell lines were used for the in vitro studies: a human breast cancer cell line (MCF7 cells), a human glial cell line (G1 cells) and a mouse fibroblast cell line (L929 cells, control cells). The better targeting efficacy of the dual-targeted NPs (higher specificity and uptake than single-targeted NPs) was clearly evidenced by the internalisation studies and cytotoxicity assays. The latter also demonstrated the synergistic effect of using curcumin and 5FU together, therefore resulting in an enhanced therapeutic effect compared to the use of a single drug. The effects of simultaneous drug release and magnetic hyperthermia (frequency $=305 \mathrm{kHz}$; amplitude $=18.3 \mathrm{kA} \mathrm{m}^{-1}$ ) were evaluated after 60 and $120 \mathrm{~min}$ of treatment. The use of nontargeted NPs resulted in a high reduction of the cell viability for both healthy and cancer cells, due to the lack of specificity of the nanovector. In contrast, treatment performed with the dualtargeted NPs shows a radical cytotoxic effect on cancer cells, without really damaging the healthy cells. Thanks to the dual targeting ability, both heat and drugs are targeted to cancerous tissue. The cell viability after $60 \mathrm{~min}$ and $120 \mathrm{~min}$ of treatment was $41 \%$ and $28 \%$ for the MCF7 cells, and $38 \%$ and $26 \%$ for the G1 cells, respectively. Even after removal of the AMF, the cell viability continues to decrease. $12 \mathrm{~h}$ after the hyperthermic treatment, the cell viability was $16 \%$ and $11 \%$ for MCF7 and G1 cells, respectively, while $24 \mathrm{~h}$ after, the cell viability was reduced to $7 \%$ and $4 \%$ for MCF7 and G1 cells, respectively, which clearly demonstrates the synergistic effect of the combined treatment.

In another recent study, the authors chose to use $\mathrm{Mn}-\mathrm{Zn}$ ferrite NPs for their $T_{\mathrm{c}}$ close to body temperature and adjustable (by varying the ratio of $\mathrm{Zn}^{2+}$ to $\mathrm{Mn}^{2+}$ ), which enables the control of the maximum heating temperature reached during the hyperthermia experiment. ${ }^{\mathbf{1 6 6}} \mathrm{Mn}_{0: 2} \mathrm{Zn}_{0: 8} \mathrm{Fe}_{2} \mathrm{O}_{4}$ NPs $(7 \mathrm{~nm})$ were encapsulated in a thermo-sensitive copolymer composed of $N$-isopropylacrylamide (NIPAAm) and $N$-hydroxymethylacrylamide (HMAAm). A 7 : 1 PNIPAAm/HMAAm molar ratio was selected, as it was found that its LCST was equal to $40.1{ }^{\circ} \mathrm{C}$. The polymeric NPs were loaded with $10 \%, 8 \%$ and $6 \%$ of MNPs and subjected to an $\mathrm{AMF}$ (frequency $=80 \mathrm{kHz}$; amplitude $=6.5 \mathrm{kA} \mathrm{m}^{-1}$ ), giving nanocarriers with a maximum self-heating temperature reached within 6-10 min of $44.5{ }^{\circ} \mathrm{C}, 42.9{ }^{\circ} \mathrm{C}$ and $40.5{ }^{\circ} \mathrm{C}$, respectively. Therefore, by choosing a loading percentage of $8 \%$, magnetic polymeric NPs with a maximum self-heating temperature of $42.9{ }^{\circ} \mathrm{C}$ and a LCST of $40.1{ }^{\circ} \mathrm{C}$ are obtained. This is a very interesting property, because as discussed previously, the thermal enhancement of the cytotoxic activity of many anti- cancer agents is maximized at temperatures between 40.5 and $43{ }^{\circ} \mathrm{C}$. A maximum self-heating temperature close to $43{ }^{\circ} \mathrm{C}$ enables to stay in the mild hyperthermia temperature range to fully benefit the synergistic effect of simultaneous hyperthermia and chemotherapy.

Hydrogels consist of a three-dimensional polymer network containing large quantities of water, but remain insoluble due to their cross-linked structure. The properties of a hydrogel such as its elasticity, degradation rate or swelling ratio can be tuned by modifying the hydrogel parameters (i.e. polymer, block lengths, cross-linker ratio, etc.). Nanohydrogels are used as drug delivery systems. Drugs are entrapped in the polymer matrix, and released via diffusion or matrix degradation. MNPs can also be incorporated into the hydrogel matrix.

Thermo-sensitive nanohydrogels are formed by cross-linking thermo-sensitive polymers, and the final LCST of the nanohydrogel can be tuned by changing the polymer ratio. Above the LCST, the nanohydrogel becomes hydrophobic and shrink, therefore expulsing water molecules and drugs.

A concentric layered magnetic chitosan hydrogel with controlled layer numbers and layer thicknesses was recently synthesised via a facile alternate alkali treatment method. ${ }^{\mathbf{1 6 7}}$ Magnetite NPs and the chemotherapeutic drug adriamycin were incorporated into the hydrogel matrix. The drug release behaviour was estimated by switching ON and OFF a low frequency alternating magnetic field (LAMF). An increased rate of drug release is observed when the LAMF is ON. In this study, magnetic hyperthermia is not believed to be the trigger of the drug release, but rather volume shrinkage of the hydrogel due to the magnetisation of the MNPs, which promote drug release by expelling the drug out of the hydrogel.

Jaiswal et al. developed dual $\mathrm{pH}$ and temperature stimuliresponsive nanohydrogels by incorporating magnetite NPs into a polymeric matrix based on poly( $N$-isopropylacrylamide $)$-chitosan, with a LCST optimised around $42{ }^{\circ} \mathrm{C} .{ }^{168}$ DOX was used as a chemotherapeutic drug and the $\mathrm{pH}$ and temperature enhanced release was observed in an acid environment ( $\mathrm{pH} 4.6)$ and hyperthermia temperature $\left(42^{\circ} \mathrm{C}\right)$. The cell killing effect of the drug loaded magnetic nanohydrogels was assessed on MCF7 cells (human breast cell line) and HeLa cells (cervical carcinoma cell line). The combined treatment yielded up to $85 \%$ cell death, which was significantly higher than the cell death efficacy achieved by hyperthermia alone.

3.3.4 Core/shell nanoparticles. Core/shell NPs are particularly relevant for combined modalities of cancer therapy. Indeed, a metallic core can endow the NPs with the desired magnetic properties for hyperthermia applications, while an organic shell can provide drug loading capability. Moreover, the coating can also provide increased colloidal stability (prevents anisotropic magnetic dipolar attractions between MNPs), chemical stability (i.e. prevents any further oxidation), biocompatibility and reduce toxicity. The polymer can be grafted onto the MNP surface (functionalising the MNPs by covalently binding the polymer) by two different approaches. ${ }^{169}$ In the first one, called "grafting to or grafting onto", an endfunctionalised polymer is used with suitable terminal groups to directly bind to the MNP surface. The second one, called 
"grafting from", the polymerisation proceeds from the surface thanks to an initiator molecule preliminary fixed on the MNP surface. Finally, simpler but less reliable, the polymer can be attached to the MNP surface by non-covalent interactions, such as electrostatic or van der Waals interactions. There are two major types of core/shell NP delivery system: the drug is physically loaded into the polymer shell and the drug is covalently bonded to the polymer/ligand forming the shell of the MNPs. In the latter, the drug release mechanism often involves heat inducing bond cleavage. In either case, it has been demonstrated in vitro that DOX has higher cytotoxicity toward cancer cells when it is conjugated to iron oxide NPs covalently or electrostatically compared to free DOX, most likely due to higher cellular uptake through endocytosis compared to passive diffusion. ${ }^{\mathbf{1 7 0}}$

3.3.4.1 Physical drug loading. Physical drug loading in the polymer shell of the MNPs is generally obtained by hydrophobic/electrostatic interactions and is generally quite simple to realise. For efficient nanovectors, a high drug loading efficiency and rapid "on demand" release are desirable while drug leakage through the polymer layer should be avoided. A recent study has shown promising results with a $\mathrm{pH}$-responsive system in the drug release behaviour and cell killing effect with the combined therapy in the treatment of ovarian cancer. ${ }^{171}$ Iron oxide NPs $(28.5 \mathrm{~nm})$ were synthesised and coated with three different layers, forming a reservoir for drug loading ability: oleic acid, poly(maleic anhydride-alt-1-octadecene) (PMAO) and poly(ethylene-imine) (PEI). DOX was then encapsulated into the MNP polymeric shell and the MNPs were further modified with a polyethylene glycol (PEG) layer for improved colloidal stability and increased blood circulation time. Finally, the MNPs were functionalised with a targeting ligand to human ovarian cancer cells: Luteinizing Hormone-Releasing Hormone (LHRH) peptide. This system will be called LHRH-PEG-DOX-IONPs (97.1 $\mathrm{nm})$. The nanoformulation is $\mathrm{pH}$-sensitive, and therefore the drug release behaviour was evaluated at $\mathrm{pH} 5.5 \mathrm{(pH}$ found in tumour) and $\mathrm{pH} 7.4$ (physiological $\mathrm{pH}$ ). At $\mathrm{pH}=7.4$, only $17.6 \%$ of the loaded DOX were released after $72 \mathrm{~h}$ of incubation. However, at pH 5.5, 91.1\% of the loaded DOX were released after $72 \mathrm{~h}$ of incubation, with burst release within the first $2 \mathrm{~h}$ $(44.7 \%)$. Indeed, DOX is loaded through electrostatic interactions with the negatively charged carboxyl groups of the amphiphilic polymer. The release of DOX is accelerated at acidic $\mathrm{pH}$ because it reduces the interaction with protonated carboxylic groups. It also increases the solubility of DOX in aqueous solution due to the protonation of the primary amine of DOX molecules. This drug release behaviour enables limited release of the drug into the blood stream, while quick release can be obtained at cancer sites. The hyperthermia potential of the DOX free system was evaluated in vitro on an A2780/AD human ovarian carcinoma cell line, with an iron concentration of $15 \mu \mathrm{g} \mathrm{mL} \mathrm{m}^{-1}$. The experiments were carried out at two temperatures, $40{ }^{\circ} \mathrm{C}$ and $44{ }^{\circ} \mathrm{C}$, with an $\mathrm{AMF}$ of constant frequency $(393 \mathrm{kHz})$ and the magnetic field amplitude set at $33.5 \mathrm{kA} \mathrm{m}^{-1}$ (for $44{ }^{\circ} \mathrm{C}$ ) and $21.2 \mathrm{kA} \mathrm{m}^{-1}$ (for $40{ }^{\circ} \mathrm{C}$ ), and an exposure time of $30 \mathrm{~min}$. The experiments resulted in $95 \%$ and $72 \%$ cell death for hyperthermia at $44^{\circ} \mathrm{C}$ and $40{ }^{\circ} \mathrm{C}$, respectively.
Thus, hyperthermia at $44{ }^{\circ} \mathrm{C}$ has a direct cell killing effect. In order to assess the efficacy of the combined treatment, $15 \mu \mathrm{g}$ Fe/ $\mathrm{mL}$ of LHRH-PEG-DOX-IONPs were loaded with $1 \mu \mathrm{g} \mathrm{mL} \mathrm{m}^{-1}$ of DOX and subjected to an AMF under mild hyperthermia conditions $\left(40{ }^{\circ} \mathrm{C}\right)$. The effect of DOX alone resulted in a cell viability decrease by $70 \%$ while the combined treatment had a 95\% cell killing effect. Thus, the combined treatment shows a superior efficacy to either chemotherapy or mild hyperthermia as stand-alone therapy and is preferable in many ways because of the lower temperature and drug concentration used, thereby minimizing side effects and damage to healthy tissues. Electrostatic interactions were also used to load DOX into $\mathrm{MgFe}_{2} \mathrm{O}_{4}$ magnetic nanoassemblies coated with PEG-diacid. ${ }^{172}$ A loading efficiency of $80 \%$ was achieved and $75-80 \%$ of DOX was released under acidic $\mathrm{pH}$ (5.4) compared to only $20-25 \%$ at physiological $\mathrm{pH}$ (7.4), within $24 \mathrm{~h}$. The synergistic effect of DOX combined with hyperthermia was once more observed, with up to $90 \%$ cell death (against 45\% and 65\% cell death for magnetic hyperthermia alone and chemotherapy alone, respectively).

Barick et al. developed pH-responsive peptide mimic shell cross-linked magnetic nanocarriers (PMNCs) for combination therapy. ${ }^{173}$ Magnetite NPs $(10 \mathrm{~nm})$ were functionalised with glycine and the free amine groups are utilised for further conjugation with the peptide L-arginine to obtain PMNCs with both amine and carboxylic terminal groups (50 nm). The NPs were coated with a peptide, because peptides can enhance the cellular uptake, have low toxicity and are $\mathrm{pH}$-responsive. The $\mathrm{pH}$ of zero point charge of PMNCs was estimated to be 5.4, meaning that the surface is charged positively at $\mathrm{pH}<5.4$ and negatively at $\mathrm{pH}>5.4$. The reversal of the surface charge can be exploited for the purpose of drug delivery: the drug, loaded in the shell, is retained via electrostatic interactions, and released upon the change of surface charge. DOX is used as a model of cationic chemotherapeutic agents to study the drug loading and release behaviour at $\mathrm{pH} 4,5$ and 7.3. They observed that the loading efficiency was strongly dependent on the ratio of PMNCs to DOX and achieved a maximum DOX loading efficiency of $80 \%$ at PMNCs to DOX ratio of 10 . The DOX release studies show an increase in the release rate with a decreasing $\mathrm{pH}$ : only $7 \%$ of DOX was released at $\mathrm{pH} 7.3$ while the release was complete at $\mathrm{pH} 4$. The time needed for the release of $50 \%$ of DOX was found to be around $30 \mathrm{~min}$ and $45 \mathrm{~min}$ at $\mathrm{pH} 4$ and 5, respectively. The potential of the DOX loaded PMNCs was investigated on HeLa cells for the combined therapy, after only $10 \mathrm{~min}$ of AMF exposure (frequency $=265 \mathrm{kHz}$; amplitude $=335 \mathrm{Oe}$ ) and a DOX concentration of $4 \mu \mathrm{M}$. The chemotherapy treatment alone (free DOX or DOX-loaded PMNCS) resulted in a cell viability decrease by $10 \%$, and hyperthermia alone (PMNCs subjected to AMF) had a $13 \%$ decreased effect on the cell viability. The cell killing effect was higher in the case of the combined therapy, as a $28 \%$ decrease in cell viability was observed. This system is interesting for the combined therapy giving the results obtained with a short time of AMF exposure and low DOX concentration. Moreover, it exhibits quasi-inexistent drug leakage through the peptide mimic shell and the amine and carboxylic terminal groups of the nanocarriers gives a lot of possibility for the conjugation of targeting ligands. 
While being efficient, the use of $\mathrm{pH}$-sensitive drug delivery systems does not allow the remote control of the drug release. Thermo-sensitive drug delivery vehicles can be used for hyperthermia-triggered drug release which offer spatial and temporal control over the drug release but also offer the possibility of "ON-OFF" release by switching ON and OFF the AMF. For example, magnetite NPs coated with $\mathrm{N}$-isopropylacrylamide-coacrylamide (P(NIPAAm-co-Am) ) with a LCST of about $40{ }^{\circ} \mathrm{C}$ show almost complete drug release after three AMF ON-OFF cycles (frequency $=60 \mathrm{kHz}$; amplitude $=6.5 \mathrm{kA} \mathrm{m}^{-1}$ ). ${ }^{174}$

3.3.4.2 Covalent drug loading. The advantage of the conjugated drugs to the MNP surface via a labile bond is that no leakage of the drug through the polymer shell is possible. This design involves the cleavage of the bond used to conjugate the drug to the MNP in response to a stimulus. The drug can therefore be magnetically guided at the right location and activated at the right time, limiting systematic effects to a great extent. For the purpose of thermo-chemotherapy, heat labile bonds are particularly relevant, because the heat produced by the MNPs subjected to an AMF would induce the bond cleavage. For example, in the following study, the authors have designed a magnetic nanocarrier for thermo-chemotherapy composed of an iron oxide core functionalised with a ligand allowing the release of the drug through a combination of click reactions. ${ }^{175}$ The ligand contains a phosphonic acid group which gives strong binding to the NPs, and an alkyne group which allows a copper catalyzed 1,3-dipolar cycloaddition (CuAAC) with an azide. This reaction is used to link an azide terminated poly(ethylene oxide) monomethyl ether which provides biocompatibility, stability and antifouling properties to the NPs. The ligand also contains a furan ring making possible a DielsAlder (DA) reaction used to link a drug. In this study, a dye (tetramethylrhodamine-5-C2-maleimide (Rhd-M)) was used to investigate the potential of the nanosystem for drug delivery. The DA reaction occurs between an alkene and a diene and is thermoreversible. Therefore, the biologically active molecule can be released by provoking the retro-DA (rDA) reaction. The rDA reaction generally occurs at temperatures around 90-110 ${ }^{\circ} \mathrm{C}$. Even though those temperatures can seem really high for biological purposes, recent studies have shown the existence of local heating effects in the vicinity of MNPs leading to high temperatures at the NP surface. ${ }^{\mathbf{1 7 6 , 1 7 7}}$ This phenomenon can be exploited to kill more effectively cancer cells without a significant increase of temperature in the biological medium, or in the case of this study, trigger the drug release by initiating the rDA reaction. Indeed, the ligand has been designed to provide the cleavable bond close to the NP surface, allowing the exploitation of the local heating phenomenon. The study shows that, indeed, upon application of an AMF, the rDA reaction occurs, leading to the release of the dye Rhd-M, and thereby this design offers possibility for thermo-chemotherapy applications.

Even if heat labile bonds are particularly convenient for hyperthermia with combined chemotherapy, acid labile bonds are also widely used for drug delivery applications, as the $\mathrm{pH}$ in the tumour environment is more acidic than in blood or healthy tissue. A recent study used an acid labile imine bond to conjugate doxorubicin to magnetite NPs. ${ }^{178}$ The mechanism by which the drug is released was assumed as follows: the MNPs are taken up by endocytosis by the cancer cells, and the drug is released in acid lysosomes due to the bond cleavage in acidic conditions ( $\mathrm{pH}$ in lysosomes is between 3.5 and 5). Other acid cleavable bonds have been used recently for drug delivery purposes and could be used for the combined therapy, such as hydrazone bonds to conjugate DOX to magnetite NPs ${ }^{\mathbf{1 7 9 , 1 8 0}}$ or nanocrystal clusters ${ }^{\mathbf{1 8 1}}$ or else ester bonds to conjugate paclitaxel to iron oxide NPs. ${ }^{182}$

Finally, other possible cleavable bonds that can be used for drug delivery are redox labile bonds such as disulfide bonds. ${ }^{183}$ Indeed, the reductive tumour intracellular environment due to the elevated level of reductive glutathione in many tumour cells enables redox bond cleavage thus releasing the drug. Acid and redox cleavable bonds for use in drug delivery applications have another important advantage. Indeed, it has been noticed that a high amount of glutathione is often associated with chemotherapeutic drug-resistant cancer. ${ }^{\mathbf{1 8 4}}$ However, by releasing drugs intracellularly (as in the case of drugs conjugated by $\mathrm{pH}$ or redox cleavable bonds), drug resistance can be overcome. ${ }^{185}$

If the drug used also have a targeting ability, no cleavage of the bond conjugating the drug molecules to the MNPs is necessary. This is the case of the drug methotrexate which has been used in a recent study for thermo-chemotherapy. ${ }^{\mathbf{1 8 6}}$ Magnetite NPs were prepared by the co-precipitation method and coated with poly(ethyleneimine) (PEI). PEI is used to improve colloidal stability, and to conjugate methotrexate (MTX) through an amide bond. MTX is used for its targeting ability on the folate receptor (over-expressed in many types of cancers) and its therapeutic effect. MCF-7 cells (positive to reduced folate carriers) were used for the in vitro studies and L929 cells as control. The cellular uptake shows a more efficient and selective internalisation in the cell cytoplasm of MTX-MNPs compared to non-conjugated MNPs. The relative cell viability was estimated for MNP hyperthermia or chemotherapy alone (MTX-MNPs without application of a magnetic field) and the combined treatment. $200 \mu \mathrm{L}$ of MTX-MNPs with a MNP and MTX concentration of $25 \mathrm{mg} \mathrm{mL}^{-1}$ and $100 \mu \mathrm{M}$, respectively, were used for the measurement, at a temperature of $43{ }^{\circ} \mathrm{C}$ for 20 min (magnetic field frequency: $300 \mathrm{kHz}$; and maintaining the temperature by adjusting the amplitude of the magnetic field). The cell viabilities for the MNPs alone, MTX-MNPs without application of a magnetic field and MTX-MNPs with application of a magnetic field were decreased to $87.6 \pm 10.8 \%, 64.5 \pm 7.2 \%$ and $13.3 \pm 1.3 \%$, respectively. A true synergistic effect between hyperthermia and MTX is thus observed, demonstrating the efficiency of the MTX-MNP design.

\subsection{Examples of in vivo applications of thermo- chemotherapy}

To the best of our knowledge, there has been no clinical trial performed on drug-loaded MNP-based nano-systems for simultaneous thermo-chemotherapy. However, the fate and effectiveness of different magnetic carriers have been tested in vivo. In vivo experiments are important because the overall effects can be observed on a living subject and it is therefore the 
best way to get close from the conditions found in a human body ( $\mathrm{pH}$, complicated tumour microenvironment, etc.) which can interfere to a great extent with the fate of the nano-systems (i.e. drug pharmacokinetic, NP distribution pattern, etc.). Yoo et al. introduced resistance-free apoptosis-inducing magnetic nanoparticles (RAIN) based on $\mathrm{Zn}_{0.4} \mathrm{Fe}_{2.6} \mathrm{O}_{4}$ MNPs for simultaneous hyperthermia therapy and release of geldanamycin (GM). ${ }^{187} \mathrm{GM}$ is a heat shock protein (HSP) inhibitor and is used to prevent thermo-resistance. Indeed, consecutive hyperthermia treatment often results in the development of resistance to the cytotoxic effect of heat. ${ }^{188}$ This phenomenon is called thermoresistance and arises from the synthesis of HSPs as a response of thermal stress. Indeed, the presence of HSPs has been correlated with the natural adaptation to heat of a living organism. GM is conjugated to the MNPs via a heat labile azo linker, and complete release occurs as a consequence of magnetic hyperthermia after $60 \mathrm{~min}$ of exposure at $43{ }^{\circ} \mathrm{C}$ with an applied field of frequency $=500 \mathrm{kHz}$ and amplitude $=37.4$ $\mathrm{kA} \mathrm{m}^{-1}$. No release is observed at $37{ }^{\circ} \mathrm{C}$. The in vitro studies on MDA-MB-231 breast cancer cells revealed a 100\% cell killing efficiency after $70 \mathrm{~min}$ of treatment $\left(43{ }^{\circ} \mathrm{C}\right)$ with the RAIN, against only $25 \%$ after $80 \mathrm{~min}$ of treatment for magnetic hyperthermia alone. A strong expression of HSPs was observed after the hyperthermic treatment, while after exposure to RAIN hyperthermia, the expression of HSP was comparable to the control. Finally, MDA-MB-231 cells were transplanted into the right hind legs of nude mice and $50 \mu \mathrm{g}$ of RAIN were directly injected into the tumour. Hyperthermia at $43{ }^{\circ} \mathrm{C}$ was maintained for $30 \mathrm{~min}$. Magnetic hyperthermia was not sufficient to inhibit the tumour growth, but RAIN hyperthermia was found to completely suppress the tumour $8 \mathrm{~d}$ after single AMF exposure. The in vitro and in vivo tests confirmed that HSPs are responsible for the thermo-resistance phenomenon and that its inhibition is critical for hyperthermia induced apoptosis.

Li et al. developed truncated octahedral magnetite NPs (edge length: $22 \mathrm{~nm}$ ) coated with poly(styrene-alt-maleic acid) (PSMA) and further functionalised with PEG and poly-A polynucleotide. ${ }^{189}$ PEG chains are used to increase the blood circulation time and to bind a cancer cell targeting moiety: the antihuman epidermal growth factor receptor type 2 (anti-HER2) monoclonal antibody, while the polynucleotide has the ability to absorb the chemotherapeutic drug 5 -fluorouracil (5-FU) by forming a hydrogen bond between the adenine group of the polynucleotide and 5-FU (5-FU loaded $\mathrm{Fe}_{3} \mathrm{O}_{4} @$ anti-HER2). They demonstrated the superiority of the targeted nano-system in vitro on MBT-2 cells, a mouse bladder cancer cell line which over-expresses HER2 antigen, compared to the non-targeted one (triple the number of NPs targeting MBT-2 cells and enhance cellular uptake). MBT-2 cells were transplanted into $\mathrm{C} 3 \mathrm{H} / \mathrm{HeN}$ mice to induce bladder cancer in mice for in vivo experiments. Firstly, $50 \mu \mathrm{L}$ of a solution of 5 -FU loaded $\mathrm{Fe}_{3} \mathrm{O}_{4}$ @anti-HER2 NPs were injected intratumourally to assess the efficacy of the combined therapy on small size $\left(<50 \mathrm{~mm}^{3}\right)$ and large size $(>50$ $\mathrm{mm}^{3}$ ) tumours. The tumours were exposed to an AMF for 15 min (frequency: $1.3 \mathrm{MHz}$; amplitude: $33 \mathrm{kA} \mathrm{m}^{-1}$ ) $2 \mathrm{~h}$ later. In the case of small tumours, hyperthermia alone as well as the combined treatment led to almost total tumour regression.
However, for large tumours, hyperthermia alone was not sufficient enough to significantly inhibit tumour growth, and only hyperthermia with combined chemotherapy resulted in a significant anti-cancer effect. Secondly, the efficacy of the combined treatment was evaluated using the systematic delivery method through tail-vein injection. $200 \mu \mathrm{L}$ of 5 -FU loaded $\mathrm{Fe}_{3} \mathrm{O}_{4}$ @anti-HER2 NPs with a concentration of $500 \mu \mathrm{g}$ $\mathrm{mL}^{-1}$ were injected once per day for four consecutive days and the hyperthermia treatment was applied $24 \mathrm{~h}$ after the NPs had been injected. The combined treatment resulted in a prominent cancer regression compared to either hyperthermia or 5-FU alone. Interestingly, vital organs showed no detectable pathological findings $48 \mathrm{~h}$ after tail-vein injection while higher accumulation of 5-FU loaded $\mathrm{Fe}_{3} \mathrm{O}_{4} @$ @anti-HER2 in tumours was detected $48 \mathrm{~h}$ rather than $24 \mathrm{~h}$ post-injection. Moreover, after hyperthermia treatment, relocation of the NPs from other organs to the tumour was observed, probably due to the change in tumour vasculature in response to hyperthermia which facilitates NP extravasation. This information is highly valuable in maximizing the therapeutic effect and minimizing the side effects of the treatment. It also suggests that pre-hyperthermia treatment could be applied before injection of the NPs to increase their accumulation at the cancer site.

Wang et al. evaluated the therapeutic efficacy of $\mathrm{Mn}_{0.5} \mathrm{Zn}_{0.5} \mathrm{Fe}_{2} \mathrm{O}_{4}$ (MZF) NPs and arsenic trioxide $\left(\mathrm{As}_{2} \mathrm{O}_{3}\right)$ encapsulated in thermosensitive magnetoliposomes (TSMLs) composed of 1,2-dipalmitoylsn-glycero-3-phosphocholine (DPPC), cholesterol and vitamin E $(54: 6: 1, \mathrm{~m} / \mathrm{m})(128.2 \mathrm{~nm})$ in rabbits with a $2.0 \mathrm{~cm}$ diameter VX2 tumour in the left liver lobe. ${ }^{190} \mathrm{As}_{2} \mathrm{O}_{3}$ has a powerful antitumour effect on malignant solid tumours and was used in this study as an anti-cancer agent. The crystalline phase transition temperature of the liposome was estimated to be $42.7^{\circ} \mathrm{C}$. The drug release between $37{ }^{\circ} \mathrm{C}$ and $39^{\circ} \mathrm{C}$ was inexistent and very low at $40{ }^{\circ} \mathrm{C}$ and $41{ }^{\circ} \mathrm{C}$. Then, the release percentage jumped to $65.55 \%$ at $42{ }^{\circ} \mathrm{C}, 78.66 \%$ at $43{ }^{\circ} \mathrm{C}$ and finally reached $98.32 \%$ at $44{ }^{\circ} \mathrm{C}$. The liposomes were injected into the tumour feeding artery. Hyperthermia treatment was applied for $60 \mathrm{~min}$ with an AMF (frequency $=230 \mathrm{kHz}$; I = 30 A). The temperature reached $44{ }^{\circ} \mathrm{C}$ within $30 \mathrm{~min}$ and remained stable for the next $30 \mathrm{~min}$, benefiting from the self-heating control behaviour of MZF NPs due to their low Curie temperature. The combined treatment had the most effective anti-cancer effect, with a cell growth inhibition rate of $85.22 \%$, against $52.68 \%$ for liposomes entrapping MZF and $44.96 \%$ for liposomes entrapping $\mathrm{As}_{2} \mathrm{O}_{3}$.

\section{Conclusions and perspectives}

Water colloidal dispersion of MNPs has shown great potential for use as heat-mediators agents, and efforts in the field have led to promising preclinical and clinical studies. However, MFH is still far from achieving its full clinical potential. Most of the research on magnetic nanoparticle-mediated hyperthermia therapy has been directed toward MNPs exhibiting good biocompatibility and an improved SAR value. However, as the SAR increases with increasing frequency and amplitude of the applied field, one needs to pay careful attention to these values. Indeed, a too strong AMF may generate eddy currents and cause 
non-specific heating and therefore damaging of both healthy and cancer tissues. Nonetheless, many of the research groups used magnetic fields with an $H f$ factor exceeding the determined biologically safe threshold, which is unfortunate because the heating potential could be in fact insufficient for any applications under clinical conditions. Indeed, the higher the SAR, the lower is the MNP concentration needed to achieve the temperature range for full therapeutic efficacy, which is crucial as a too high NP concentration may have significant toxicity.

Magnetic hyperthermia combined with drug delivery does not require temperatures as high as those used for hyperthermia therapy alone. Indeed, as discussed previously, the thermal enhancement of drug cytotoxicity is maximized at mild hyperthermia temperatures, meaning that the MNPs do not need to possess such an exceptional SAR value for use in the combined therapy. Moreover, it has been proven many times through in vitro as well as in vivo studies that the combination therapy is far more effective than either hyperthermia or chemotherapy alone. As the combination of hyperthermia and chemotherapy in a same MNP-based nano-therapeutic system is relatively new, there are still some obstacles to tackle before clinical trials can be carried out. A high drug loading should be achieved and drug diffusion from the nanocarriers should be suppressed to limit systematic delivery. The pharmacokinetic and pharmacodynamic of the nanosystem needs to be studied for a better comprehension and a possible increase in the treatment efficacy. However, thermo-chemotherapy by means of a magnetic nano-system gathers all the numerous advantages of $\mathrm{MFH}$ over traditional hyperthermia and controlled drug release over traditional chemotherapy. Better anti-cancer effects at lower drug therapeutic dose and lower temperatures are achieved with the combined therapy. The possibility of triggering the drug release in cancer sites thanks to the use of $\mathrm{pH}$ - or thermo-sensitive-based nanocarriers is a particularly attractive feature to control the spatiotemporal release of the drug. The nano-systems can be functionalised with an active targeting moiety to increase the amount of particles delivered to the tumour site as well as the cellular uptake. The use of MNPs also gives the opportunity to target a site of interest via magnetic targeting. Finally, the efficient delivery of the nanoformulation combining MNPs and drugs can be confirmed by MRI, as MNPs and especially iron oxide NPs are effective contrast agents. ${ }^{191-194}$ Undoubtedly, MNPs have many potential applications in biomedicine, ${ }^{195}$ among them magnetic hyperthermia is perhaps the most exciting aspect and has huge amount of attention and attracts a lot of research activities. However, for this field to progress, particular attention must be paid to the synthesis and biofunctionalisation of NPs to enhance their overall performance ${ }^{\mathbf{1 9 6}, 197}$ and move over understanding the mechanisms of nucleation and growth of NPs is important to obtain control over the nanoparticle synthesis and overcome current methods of trial and error. ${ }^{198}$

\section{Acknowledgements}

Nguyen T. K. Thanh thanks the Royal Society for her University Research Fellowship.

\section{Notes and references}

1 L. X. Tiefenauer, G. Kuhne and R. Y. Andres, Bioconjugate Chem., 1993, 4, 347-352.

2 Y. Hu, L. Meng, L. Niu and Q. Lu, Langmuir, 2013, 29, 91569163.

3 A. Jordan, P. Wust, R. Scholz, H. Faehling, J. Krause and R. Felix, Magnetic fluid hyperthermia (MFH), 1997.

4 M. Kallumadil, M. Tada, T. Nakagawa, M. Abe, P. Southern and Q. A. Pankhurst, J. Magn. Magn. Mater., 2009, 321, 15091513.

5 S. S. Banerjee and D. H. Chen, Chem. Mater., 2007, 19, 63456349.

6 M. Rahimi, A. Wadajkar, K. Subramanian, M. Yousef, W. N. Cui, J. T. Hsieh and K. T. Nguyen, Nanomedicine: Nanotechnology, Biology and Medicine, 2010, 6, 672-680.

7 H. Wang, T. B. Shrestha, M. T. Basel, R. K. Dani, G. M. Seo, S. Balivada, M. M. Pyle, H. Prock, O. B. Koper, P. S. Thapa, D. Moore, P. Li, V. Chikan, D. L. Troyer and S. H. Bossmann, Beilstein J. Nanotechnol., 2012, 3, 444-455. 8 S. Purushotham, P. E. Chang, H. Rumpel, I. H. Kee, R. T. Ng, P. K. Chow, C. K. Tan and R. V. Ramanujan, Nanotechnology, 2009, 20, 305101.

9 O. Veiseh, J. W. Gunn and M. Zhang, Adv. Drug Delivery Rev., 2010, 62, 284-304.

10 C. Sanson, O. Diou, J. Thevenot, E. Ibarboure, A. Soum, A. Brulet, S. Miraux, E. Thiaudiere, S. Tan, A. Brisson, V. Dupuis, O. Sandre and S. Lecommandoux, ACS Nano, 2011, 5, 1122-1140.

11 L. T. Lu, L. D. Tung, I. Robinson, D. Ung, B. Tan, J. Long, A. I. Cooper, D. G. Fernig and N. T. K. Thanh, J. Mater. Chem., 2008, 18, 2453.

12 P. Guardia, A. Labarta and X. Batlle, J. Phys. Chem. C, 2011, 115, 390-396.

13 R. Narayanan and M. A. El-Sayed, J. Phys. Chem. B, 2005, 109, 12663-12676.

14 M. Gonzales-Weimuller, M. Zeisberger and K. M. Krishnan, J. Magn. Magn. Mater., 2009, 321, 1947-1950.

15 X. Zhou, Y. Shi, L. Ren, S. Bao, Y. Han, S. Wu, H. Zhang, L. Zhong and Q. Zhang, J. Solid State Chem., 2012, 196, 138-144.

16 T. Atsumi, B. Jeyadevan, Y. Sato and K. Tohji, J. Magn. Magn. Mater., 2007, 310, 2841-2843.

17 T. T. Thuy, S. Maenosono and N. T. K. Thanh, in Magnetic Nanoparticles: From Fabrication to Clinical Applications, CRC Press, 2012, pp. 99-126.

18 B. V. Harmon, Y. S. Takano, C. M. Winterford and G. C. Gobe, Int. J. Radiat. Biol., 1991, 59, 489-501.

19 J. F. R. Kerr, C. M. Winterford and B. V. Harmon, Cancer, 1994, 73, 2013-2026.

20 J. van der Zee, Ann. Oncol., 2002, 13, 1173-1184.

21 R. D. Issels, Eur. J. Cancer, 2008, 44, 2546-2554.

22 H. R. Moyer and K. A. Delman, Int. J. Hyperthermia, 2008, 24, 251-261.

23 G. F. Baronzio and E. D. Hager, Hyperthermia in Cancer Treatment: A Primer, Springer, 2006. 
24 R. Cavaliere, E. C. Ciocatto, B. C. Giovanella, C. Heidelberger, R. O. Johnson, M. Margottini, B. Mondovi, G. Moricca and A. Rossi-Fanelli, Cancer, 1967, 20, 1351-1381.

25 R. T. Gordon, J. R. Hines and D. Gordon, Med. Hypotheses, 1979, 5, 83-102.

26 P. Golstein and G. Kroemer, Trends Biochem. Sci., 2007, 32, 37-43.

27 M. C. Willingham, J. Histochem. Cytochem., 1999, 47, 11011109.

28 B. Hildebrandt, P. Wust, O. Ahlers, A. Dieing, G. Sreenivasa, T. Kerner, R. Felix and H. Riess, Critical Reviews in Oncology/ Hematology, 2002, 43, 33-56.

29 J. R. Lepock, Int. J. Hyperthermia, 2003, 19, 252-266.

30 C. W. Song, Cancer Res., 1984, 44, 4721s-4730s.

31 C. W. Song, J. G. Rhee and S. H. Levitt, J. Natl. Cancer Inst., 1980, 64, 119-124.

32 F. K. Storm, W. H. Harrison, R. S. Elliott and D. L. Morton, Cancer Res., 1979, 39, 2245-2251.

33 D. W. Siemann, Cancer Treat. Rev., 2011, 37, 63-74.

34 M. W. Dewhirst, C. Y. Tso, R. Oliver, C. S. Gustafson, T. W. Secomb and J. F. Gross, Int. J. Radiat. Oncol., Biol., Phys., 1989, 17, 91-99.

35 L. E. Gerweck, T. G. Nygaard and M. Burlett, Cancer Res., 1979, 39, 966-972.

36 C. W. Song, H. Park and R. J. Griffin, Radiat. Res., 2001, 155, 515-528.

37 P. Wust, B. Hildebrandt, G. Sreenivasa, B. Rau, J. Gellermann, H. Riess, R. Felix and P. M. Schlag, Lancet Oncol., 2002, 3, 487-497.

38 K. Maier-Hauff, F. Ulrich, D. Nestler, H. Niehoff, P. Wust, B. Thiesen, H. Orawa, V. Budach and A. Jordan, J. Neurooncol., 2011, 103, 317-324.

39 K. Maier-Hauff, R. Rothe, R. Scholz, U. Gneveckow, P. Wust, B. Thiesen, A. Feussner, A. von Deimling, N. Waldoefner, R. Felix and A. Jordan, J. Neurooncol., 2007, 81, 53-60.

40 M. R. Manning, T. C. Cetas, R. C. Miller, J. R. Oleson, W. G. Connor and E. W. Gerner, Cancer, 1982, 49, 205-216.

41 J. van der Zee, D. G. Gonzalez, G. C. van Rhoon, J. D. P. van Dijk, W. L. J. van Putten, A. A. M. Hart and Dutch Deep Hyperthermia, Lancet, 2000, 355, 1119-1125.

42 M. R. Horsman and J. Overgaard, Clin. Oncol., 2007, 19, 418-426.

43 R. D. Issels, L. H. Lindner, J. Verweij, P. Wust, P. Reichardt, B. C. Schem, S. Abdel-Rahman, S. Daugaard, C. Salat, C. M. Wendtner, Z. Vujaskovic, R. Wessalowski, K. W. Jauch, H. R. Durr, F. Ploner, A. Baur-Melnyk, U. Mansmann, W. Hiddemann, J. Y. Blay and P. Hohenberger, Lancet Oncol., 2010, 11, 561-570.

44 R. D. Issels, S. Abdel-Rahman, C. M. Wendtner, M. H. Falk, V. Kurze, H. Sauer, U. Aydemir and W. Hiddemann, Eur. J. Cancer, 2001, 37, 1599-1608.

45 K. Sugimachi, H. Kuwano, H. Ide, T. Toge, M. Saku and Y. Oshiumi, Int. J. Hyperthermia, 1994, 10, 485-493.

46 A. Chicheł, J. Skowronek, M. Kubaszewska and M. Kanikowski, Reports of Practical Oncology \& Radiotherapy, 2007, 12, 267-275.
47 M. H. Falk and R. D. Issels, Int. J. Hyperthermia, 2001, 17, 118.

48 J. Otte, Eur. J. Pediatr., 1988, 147, 560-569.

49 G. Nedelcu, Digest Journal of Nanomaterials and Biostructures, 2008, 3, 103-107.

50 B. Thiesen and A. Jordan, Int. J. Hyperthermia, 2008, 24, 467-474.

51 A. Jordan, R. Scholz, P. Wust, H. Fähling and R. Felix, J. Magn. Magn. Mater., 1999, 201, 413-419.

52 P. Cherukuri, E. S. Glazer and S. A. Curley, Adv. Drug Delivery Rev., 2010, 62, 339-345.

53 M. Arruebo, R. Fernández-Pacheco, M. R. Ibarra and J. Santamaría, Nano Today, 2007, 2, 22-32.

54 R. Hergt, S. Dutz, R. Müller and M. Zeisberger, J. Phys.: Condens. Matter, 2006, 18, S2919-S2934.

55 J. P. Fortin, F. Gazeau and C. Wilhelm, Eur. Biophys. J., 2008, 37, 223-228.

56 M. Suto, Y. Hirota, H. Mamiya, A. Fujita, R. Kasuya, K. Tohji and B. Jeyadevan, J. Magn. Magn. Mater., 2009, 321, 14931496.

57 R. Kotitz, W. Weitschies, L. Trahms and W. Semmler, J. Magn. Magn. Mater., 1999, 201, 102-104.

58 R. Kotitz, P. C. Fannin and L. Trahms, J. Magn. Magn. Mater., 1995, 149, 42-46.

59 M. Levy, C. Wilhelm, J.-M. Siaugue, O. Horner, J.-C. Bacri and F. Gazeau, J. Phys.: Condens. Matter, 2008, 20, 204133.

60 R. E. Rosensweig, J. Magn. Magn. Mater., 2002, 252, 370-374.

61 I. Sharifi, H. Shokrollahi and S. Amiri, J. Magn. Magn. Mater., 2012, 324, 903-915.

62 A. H. Habib, C. L. Ondeck, P. Chaudhary, M. R. Bockstaller and M. E. McHenry, J. Appl. Phys., 2008, 103, 07 A307.

63 R. Kappiyoor, M. Liangruksa, R. Ganguly and I. K. Puri, J. Appl. Phys., 2010, 108, 094702.

64 X. L. Liu, H. M. Fan, J. B. Yi, Y. Yang, E. S. G. Choo, J. M. Xue, D. D. Fan and J. Ding, J. Mater. Chem., 2012, 22, 8235.

65 R. Hergt, R. Hiergeist, M. Zeisberger, G. Glockl, W. Weitschies, P. Ramirez, I. Hilger and W. A. Kaiser, J. Magn. Magn. Mater., 2004, 280, 358-368.

66 R. Hergt and S. Dutz, J. Magn. Magn. Mater., 2007, 311, 187192.

67 E. Natividad, M. Castro and A. Mediano, Appl. Phys. Lett., 2008, 92, 093116.

68 I. Andreu and E. Natividad, Int. J. Hyperthermia, 2013, 29, 739-751.

69 S. Huang, S. Y. Wang, A. Gupta, D. A. Borca-Tasciuc and S. J. Salon, Meas. Sci. Technol., 2012, 23, 035701.

70 Y. Zhai, H. Xie and H. C. Gu, Int. J. Hyperthermia, 2009, 25, 65-71.

71 A. Ito, K. Tanaka, H. Honda, S. Abe, H. Yamaguchi and T. Kobayashi, J. Biosci. Bioeng., 2003, 96, 364-369.

72 M. Johannsen, U. Gneveckow, L. Eckelt, A. Feussner, N. Waldofner, R. Scholz, S. Deger, P. Wust, S. A. Loening and A. Jordan, Int. J. Hyperthermia, 2005, 21, 637-647.

73 H. S. Huang and J. F. Hainfeld, Int. J. Nanomed., 2013, 8, 2521-2532.

74 H. Kobayashi, R. Watanabe and P. L. Choyke, Theranostics, 2014, 4, 81-89. 
75 S. Acharya and S. K. Sahoo, Adv. Drug Delivery Rev., 2011, 63, 170-183.

76 Y. Matsumura and H. Maeda, Cancer Res., 1986, 46, 63876392.

77 H. Maeda, J. Wu, T. Sawa, Y. Matsumura and K. Hori, J. Controlled Release, 2000, 65, 271-284.

78 H. Maeda, in Advances in Enzyme Regulation, ed. G. Weber, 2001, vol. 41, pp. 189-207.

79 A. K. Iyer, G. Khaled, J. Fang and H. Maeda, Drug Discovery Today, 2006, 11, 812-818.

80 J. Fang, H. Nakamura and H. Maeda, Adv. Drug Delivery Rev., 2011, 63, 136-151.

81 H. Maeda, J. Controlled Release, 2012, 164, 138-144.

82 H. Maeda, H. Nakamura and J. Fang, Adv. Drug Delivery Rev., 2013, 65, 71-79.

83 K. M. Krishnan, IEEE Trans. Magn., 2010, 46, 2523-2558.

84 S. Saito, M. Tsugeno, D. Koto, Y. Mori, Y. Yoshioka, S. Nohara and K. Murase, Int. J. Nanomed., 2012, 7, 54155421.

85 S. R. Saptarshi, A. Duschl and A. L. Lopata, J. Nanobiotechnol., 2013, 11, 26.

86 C. Gruttner, K. Muller, J. Teller, F. Westphal, A. Foreman and R. Ivkov, J. Magn. Magn. Mater., 2007, 311, 181-186.

87 H. C. Yang, K. W. Huang, S. H. Liao, H. E. Horng, J. J. Chieh, H. H. Chen, M. J. Chen, K. L. Chen and L. M. Wang, Appl. Phys. Lett., 2013, 102.

88 A. M. Prantner, C. V. Nguyen and N. Scholler, J. Biomed. Nanotechnol., 2013, 9, 1686-1697.

89 K. L. Vigor, P. G. Kyrtatos, S. Minogue, K. T. Al-Jamal, H. Kogelberg, B. Tolner, K. Kostarelos, R. H. Begent, Q. A. Pankhurst, M. F. Lythgoe and K. A. Chester, Biomaterials, 2010, 31, 1307-1315.

90 M. Kumar, G. Singh, V. Arora, S. Mewar, U. Sharma, N. R. Jagannathan, S. Sapra, A. K. Dinda, S. Kharbanda and H. Singh, Int. J. Nanomed., 2012, 7, 3503-3516.

91 A. Karmakar, Y. Xu, M. W. Mahmood, Y. B. Zhang, L. M. Saeed, T. Mustafa, S. Ali, A. R. Biris and A. S. Biris, J. Mater. Chem., 2011, 21, 12761-12769.

92 L. Y. Jie, L. L. Cai, L. J. Wang, X. Y. Ying, R. S. Yu, M. M. Zhang and Y. Z. Du, Int. J. Nanomed., 2012, 7, 3981-3989.

93 O. Veiseh, F. M. Kievit, C. Fang, N. Mu, S. Jana, M. C. Leung, H. Mok, R. G. Ellenbogen, J. O. Park and M. Q. Zhang, Biomaterials, 2010, 31, 8032-8042.

94 E. K. Lim, B. Kim, Y. Choi, Y. Ro, E. J. Cho, J. H. Lee, S. H. Ryu, J. S. Suh, S. Haam and Y. M. Huh, J. Biomed. Mater. Res., Part A, 2014, 102, 49-59.

95 M. K. Yu, D. Kim, I.-H. Lee, J.-S. So, Y. Y. Jeong and S. Jon, Small, 2011, 7, 2241-2249.

96 K. Pala, A. Serwotka, F. Jelen, P. Jakimowicz and J. Otlewski, Int. J. Nanomed., 2014, 9, 67-76.

97 J. P. Fortin-Ripoche, M. S. Martina, F. Gazeau, C. Menager, C. Wilhelm, J. C. Bacri, S. Lesieur and O. Clement, Radiology, 2006, 239, 415-424.

98 G. D. Zulauf, B. S. Trembly, A. J. Giustini, B. R. Flint, R. R. Strawbridge and P. J. Hoopes, Energy-Based Treatment of Tissue and Assessment VII, 2013, 8584.
99 J. T. Jang, H. Nah, J. H. Lee, S. H. Moon, M. G. Kim and J. Cheon, Angew. Chem., Int. Ed. Engl., 2009, 48, 1234-1238.

100 C. Gruttner, K. Muller, J. Teller and F. Westphal, Int. J. Hyperthermia, 2013, 29, 777-789.

101 N. T. K. Thanh and L. A. W. Green, Nano Today, 2010, 5, 213-230.

102 M. Faraji, Y. Yamini and M. Rezaee, J. Iran. Chem. Soc., 2010, 7, 1-37.

103 R. Hao, R. J. Xing, Z. C. Xu, Y. L. Hou, S. Gao and S. H. Sun, Adv. Mater., 2010, 22, 2729-2742.

104 A. G. Kolhatkar, A. C. Jamison, D. Litvinov, R. C. Willson and T. R. Lee, Int. J. Mol. Sci., 2013, 14, 15977-16009.

105 J. Carrey, B. Mehdaoui and M. Respaud, J. Appl. Phys., 2011, 109.

106 M. Sedlacik, R. Moucka, Z. Kozakova, N. E. Kazantseva, V. Pavlinek, I. Kuritka, O. Kaman and P. Peer, J. Magn. Magn. Mater., 2013, 326, 7-13.

107 M. Ma, Y. Wu, J. Zhou, Y. Sun, Y. Zhang and N. Gu, J. Magn. Magn. Mater., 2004, 268, 33-39.

108 M. R. Barati, C. Selomulya and K. Suzuki, J. Appl. Phys., 2014, 115, $17 \mathrm{~B} 522$.

109 P. de la Presa, Y. Luengo, M. Multigner, R. Costo, M. P. Morales, G. Rivero and A. Hernando, J. Phys. Chem. C, 2012, 116, 25602-25610.

110 M. Song, Y. Zhang, S. Hu, L. Song, J. Dong, Z. Chen and N. Gu, Colloids Surf., A, 2012, 408, 114-121.

111 P. Hugounenq, M. Levy, D. Alloyeau, L. Lartigue, E. Dubois, V. Cabuil, C. Ricolleau, S. Roux, C. Wilhelm, F. Gazeau and R. Bazzi, J. Phys. Chem. C, 2012, 116, 15702-15712.

112 S. Larumbe, C. Gomez-Polo, J. I. Perez-Landazabal and J. M. Pastor, J. Phys.: Condens. Matter, 2012, 24, 266007.

113 P. B. Shete, R. M. Patil, N. D. Thorat, A. Prasad, R. S. Ningthoujam, S. J. Ghosh and S. H. Pawar, Appl. Surf. Sci., 2014, 288, 149-157.

114 N. D. Thorat, V. M. Khot, A. B. Salunkhe, A. I. Prasad, R. S. Ningthoujam and S. H. Pawar, J. Phys. D: Appl. Phys., 2013, 46, 105003.

115 N. D. Thorat, V. M. Khot, A. B. Salunkhe, R. S. Ningthoujam and S. H. Pawar, Colloids Surf., B, 2013, 104, 40-47.

116 M. R. Barati, K. Suzuki, C. Selomulya and J. S. Garitaonandia, IEEE Trans. Magn., 2013, 49, 3460-3463.

117 E. Natividad, M. Castro, G. Goglio, I. Andreu, R. Epherre, E. Duguet and A. Mediano, Nanoscale, 2012, 4, 3954-3962.

118 A. H. Yao, F. R. Ai, D. P. Wang, W. H. Huang and X. C. Zhang, Mater. Sci. Eng., C, 2009, 29, 2525-2529.

119 Y. Akin, I. M. Obaidat, B. Issa and Y. Haik, Cryst. Res. Technol., 2009, 44, 386-390.

120 G. Ferk, M. Drofenik, D. Lisjak, A. Hamler, Z. Jaglicic and D. Makovec, J. Magn. Magn. Mater., 2014, 350, 124-128.

121 M. T. Basel, S. Balivada, H. W. Wang, T. B. Shrestha, G. M. Seo, M. Pyle, G. Abayaweera, R. Dani, O. B. Koper, M. Tamura, V. Chikan, S. H. Bossmann and D. L. Troyer, Int. J. Nanomed., 2012, 7, 297-306.

122 M. Lin, D. Zhang, J. Huang, J. Zhang, W. Xiao, H. Yu, L. Zhang and J. Ye, Nanotechnology, 2013, 24, 255101. 
123 T. Araya, K. Kasahara, S. Nishikawa, H. Kimura, T. Sone, H. Nagae, Y. Ikehata, I. Nagano and M. Fujimura, OncoTargets Ther., 2013, 6, 237-242.

124 L.-Y. Zhao, J.-Y. Liu, W.-W. Ouyang, D.-Y. Li, L. Li, L.-Y. Li and J.-T. Tang, Chin. Phys. B, 2013, 22, 108104.

125 J. P. May and S.-D. Li, Expert Opin. Drug Delivery, 2013, 10, 511-527.

126 W. Rao, Z.-S. Deng and J. Liu, CRC Crit. Rev. Bioeng., 2010, 38, 101-116.

127 M. Urano, M. Kuroda and Y. Nishimura, Int. J. Hyperthermia, 1999, 15, 79-107.

128 J. M. C. Bull, Cancer Res., 1984, 44, 4853-4856.

129 Y. Itoh, Y. Yamada, Y. Kazaoka, T. Ishiguchi and N. Honda, Exp. Ther. Med., 2010, 1, 319-323.

130 Z. H. Siddik, Oncogene, 2003, 22, 7265-7279.

131 C. F. Thorn, C. Oshiro, S. Marsh, T. Hernandez-Boussard, H. McLeod, T. E. Klein and R. B. Altman, Pharmacogenet. Genomics, 2011, 21, 440-446.

132 Y. N. Wu, S. M. Mikulski, W. Ardelt, S. M. Rybak and R. J. Youle, J. Biol. Chem., 1993, 268, 10686-10693.

133 A. Saxena, S. K. Saxena and K. Shogen, Anticancer Res., 2009, 29, 1067-1071.

134 M. Urano and C. C. Ling, Int. J. Hyperthermia, 2002, 18, 307315.

135 K. Nakao, Y. Otsuki, Y. Akao, Y. Ito, O. Marukawa, S. Tachibana, M. Kawakami and S. Sasaki, Med. Electron Microsc., 2000, 33, 44-50.

136 A. A. Petryk, A. J. Giustini, R. E. Gottesman, P. A. Kaufman and P. J. Hoopes, Int. J. Hyperthermia, 2013, 29, 845-851.

137 P. J. Tofilon, V. Dasilva, P. H. Gutin and D. F. Deen, Radiat. Res., 1985, 103, 373-382.

138 E. Gabano, D. Colangelo, A. R. Ghezzi and D. Osella, J. Inorg. Biochem., 2008, 102, 629-635.

139 K. Komatsu, R. C. Miller and E. J. Hall, Br. J. Cancer, 1988, 57, 59-63.

140 R. C. Miller, M. Richards, C. Baird, S. Martin and E. J. Hall, Int. J. Hyperthermia, 1994, 10, 89-99.

141 R. Tang, Z. G. Zhu, Y. Qu, H. F. Li, Y. B. Ji, Q. Cai, B. Ya Liu, M. Yan, H. R. Yin and Y. Z. Lin, Oncol. Rep., 2006, 16, 631641.

142 B. P. Timko, T. Dvir and D. S. Kohane, Adv. Mater., 2010, 22, 4925-4943.

143 M. Mahmoudi, S. Sant, B. Wang, S. Laurent and T. Sen, Adv. Drug Delivery Rev., 2011, 63, 24-46.

144 P. Bawa, V. Pillay, Y. E. Choonara and L. C. du Toit, Biomed. Mater., 2009, 4, 022001.

145 K. Cho, X. Wang, S. Nie, Z. G. Chen and D. M. Shin, Clin. Cancer Res., 2008, 14, 1310-1316.

146 S. Bibi, E. Lattmann, A. R. Mohammed and Y. Perrie, J. Microencapsulation, 2012, 29, 262-276.

147 M. A. Ward and T. K. Georgiou, Polymers, 2011, 3, 12151242.

148 P. Theato, B. S. Sumerlin, R. K. O'Reilly and T. H. Epps, Chem. Soc. Rev., 2013, 42, 7055-7056.

149 C. D. H. Alarcon, S. Pennadam and C. Alexander, Chem. Soc. Rev., 2005, 34, 276-285.
150 C. S. Kumar and F. Mohammad, Adv. Drug Delivery Rev., 2011, 63, 789-808.

151 A. L. Klibanov, K. Maruyama, V. P. Torchilin and L. Huang, FEBS Lett., 1990, 268, 235-237.

152 M. R. Faria, M. M. Cruz, M. C. Goncalves, A. Carvalho, G. Feio and M. B. F. Martins, Int. J. Pharm., 2013, 446, 183-190.

153 D. Qiu, X. Q. An, Z. Y. Chen and X. Y. Ma, Chem. Phys. Lipids, 2012, 165, 563-570.

154 A. M. Ponce, Z. Vujaskovic, F. Yuan, D. Needham and M. W. Dewhirst, Int. J. Hyperthermia, 2006, 22, 205-213.

155 C. D. Landon, J. Y. Park, D. Needham and M. W. Dewhirst, Open Nanomed. J., 2011, 3, 38-64.

156 T. Ta and T. M. Porter, J. Controlled Release, 2013, 169, 112125.

157 D. Qiu and X. An, Colloids Surf., B, 2013, 104, 326-329.

158 P. Kulshrestha, M. Gogoi, D. Bahadur and R. Banerjee, Colloids Surf., B, 2012, 96, 1-7.

159 H. Wei, R. X. Zhuo and X. Z. Zhang, Prog. Polym. Sci., 2013, 38, 503-535.

160 J. Gong, M. W. Chen, Y. Zheng, S. P. Wang and Y. T. Wang, J. Controlled Release, 2012, 159, 312-323.

161 M. Talelli and W. E. Hennink, Nanomedicine, 2011, 6, 12451255.

162 J. R. McDaniel, M. W. Dewhirst and A. Chilkoti, Int. J. Hyperthermia, 2013, 29, 501-510.

163 D. H. Kim, E. A. Vitol, J. Liu, S. Balasubramanian, D. J. Gosztola, E. E. Cohen, V. Novosad and E. A. Rozhkova, Langmuir, 2013, 29, 7425-7432.

164 M. Elsabahy and K. L. Wooley, Chem. Soc. Rev., 2012, 41, 2545-2561.

165 S. Balasubramanian, A. R. Girija, Y. Nagaoka, S. Iwai, M. Suzuki, V. Kizhikkilot, Y. Yoshida, T. Maekawa and S. D. Nair, Int. J. Nanomed., 2014, 9, 437-459.

166 J. B. Li, Y. Qu, J. Ren, W. Z. Yuan and D. L. Shi, Nanotechnology, 2012, 23, 505706.

167 Y. Wang, B. Li, Y. Zhou, Z. Han, Y. Feng and D. Wei, J. Controlled Release, 2013, 172, e90.

168 M. K. Jaiswal, A. Pradhan, R. Banerjee and D. Bahadur, J. Nanosci. Nanotechnol., 2014, 14, 4082-4089.

169 S. K. Kumar, N. Jouault, B. Benicewicz and T. Neely, Macromolecules, 2013, 46, 3199-3214.

170 M. I. Majeed, Q. W. Lu, W. Yan, Z. Li, I. Hussain, M. N. Tahir, W. Tremel and B. Tan, J. Mater. Chem. B, 2013, 1, 2874-2884.

171 O. Taratula, R. K. Dani, C. Schumann, H. Xu, A. Wang, H. Song, P. Dhagat and O. Taratula, Int. J. Pharm., 2013, 458, 169-180.

172 S. Kumar, A. Daverey, N. K. Sahu and D. Bahadur, J. Mater. Chem. B, 2013, 1, 3652-3660.

173 K. C. Barick, S. Singh, N. V. Jadhav, D. Bahadur, B. N. Pandey and P. A. Hassan, Adv. Funct. Mater., 2012, 22, 4975-4984.

174 A. H. Yao, Q. Chen, F. R. Ai, D. P. Wang and W. H. Huang, J. Mater. Sci.: Mater. Med., 2011, 22, 2239-2247.

175 T. T. T. N'Guyen, H. T. T. Duong, J. Basuki, V. Montembault, S. Pascual, C. Guibert, J. Fresnais, C. Boyer, 
M. R. Whittaker, T. P. Davis and L. Fontaine, Angew. Chem., Int. Ed., 2013, 52, 14152-14156.

176 M. Creixell, A. C. Bohorquez, M. Torres-Lugo and C. Rinaldi, ACS Nano, 2011, 5, 7124-7129.

177 B. Kozissnik, A. C. Bohorquez, J. Dobson and C. Rinaldi, Int. J. Hyperthermia, 2013, 29, 706-714.

178 Z. Zhao, D. Huang, Z. Yin, X. Chi, X. Wang and J. Gao, J. Mater. Chem., 2012, 22, 15717-15725.

179 Y. L. Chang, X. L. Meng, Y. L. Zhao, K. Li, B. Zhao, M. Zhu, Y. P. Li, X. S. Chen and J. Y. Wang, J. Colloid Interface Sci., 2011, 363, 403-409.

180 Y. L. Chang, N. A. Liu, L. Chen, X. L. Meng, Y. J. Liu, Y. P. Li and J. Y. Wang, J. Mater. Chem., 2012, 22, 9594-9601.

181 D. Li, J. Tang, C. Wei, J. Guo, S. L. Wang, D. Chaudhary and C. C. Wang, Small, 2012, 8, 2690-2697.

182 Y. L. Chang, Y. P. Li, X. L. Meng, N. A. Liu, D. X. Sun, H. Liu and J. Y. Wang, Polym. Chem., 2013, 4, 789-794.

183 Z. Luo, K. Y. Cai, Y. Hu, J. H. Li, X. W. Ding, B. L. Zhang, D. W. Xu, W. H. Yang and P. Liu, Adv. Mater., 2012, 24, 431-435.

184 G. K. Balendiran, R. Dabur and D. Fraser, Cell Biochem. Funct., 2004, 22, 343-352.

185 Y. C. Wang, F. Wang, T. M. Sun and J. Wang, Bioconjugate Chem., 2011, 22, 1939-1945.

186 F. P. Gao, Z. X. Yan, J. Zhou, Y. Y. Cai and J. T. Tang, J. Nanopart. Res., 2012, 14, 1160.

187 D. Yoo, H. Jeong, S. H. Noh, J. H. Lee and J. Cheon, Angew. Chem., Int. Ed., 2013, 52, 13047-13051.
188 S. W. Carper, J. J. Duffy and E. W. Gerner, Cancer Res., 1987, 47, 5249-5255.

189 T. J. Li, C. C. Huang, P. W. Ruan, K. Y. Chuang, K. J. Huang, D. B. Shieh and C. S. Yeh, Biomaterials, 2013, 34, 78737883.

190 L. Wang, J. Zhang, Y. L. An, Z. Y. Wang, J. Liu, Y. T. Li and D. S. Zhang, Nanotechnology, 2011, 22.

191 B. Chertok, B. A. Moffat, A. E. David, F. Q. Yu, C. Bergemann, B. D. Ross and V. C. Yang, Biomaterials, 2008, 29, 487-496.

192 C. Y. Wang, S. Ravi, U. S. Garapati, M. Das, M. Howell, J. Mallela, S. Alwarappan, S. S. Mohapatra and S. Mohapatra, J. Mater. Chem. B, 2013, 1, 4396-4405.

193 C. G. Hadjipanayis, M. J. Bonder, S. Balakrishnan, X. Wang, H. Mao and G. C. Hadjipanayis, Small, 2008, 4, 1925-1929.

194 D. Maity, P. Chandrasekharan, C. T. Yang, K. H. Chuang, B. Shuter, J. M. Xue, J. Ding and S. S. Feng, Nanomedicine, 2010, 5, 1571-1584.

195 Q. A. Pankhurst, N. T. K. Thanh, S. K. Jones and J. Dobson, J. Phys. D: Appl. Phys., 2009, 42, 224001.

196 C. Blanco-Andujar, L. D. Tung and N. T. K. Thanh, Annu. Rep. Prog. Chem., Sect. A: Inorg. Chem., 2010, 106, 553.

197 K. Stojak, H. Srikanth, M. Phan and N. T. K. Thanh, in Complex-Shaped Metal Nanoparticles: Bottom-Up Syntheses and Applications, ed. T. Sau and A. Rogach, 2012, pp. 183214.

198 N. T. Thanh, N. Maclean and S. Mahiddine, Chem. Rev., 2014, 114, 7610-7630. 